\title{
Materials Science Abounds at the 1993 MRS Fall Meeting
}

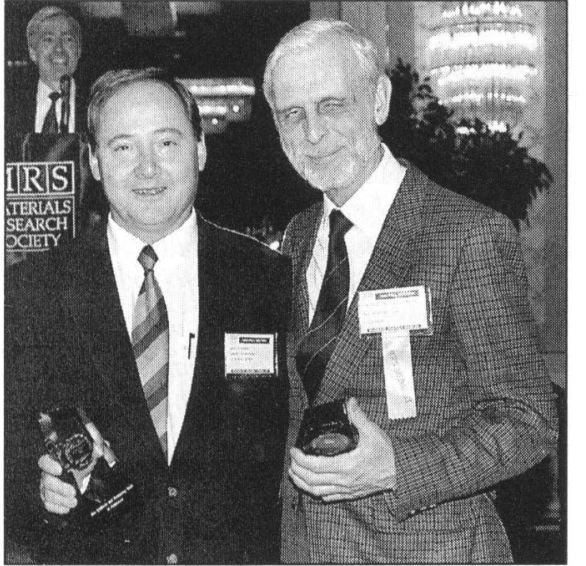

Wolfgang Krätschmer (left), professor at the Max-Planck-Institute für Kernphysik, and Donald R. Huffman, professor in the Department of Physics at the University of Arizona display their 1993 Medals Awards "for the discovery of a way to produce macroscopic quantities of the fullerenes and for elucidating many of their physical and chemical properties."

The 1993 MRS Fall Meeting in Boston brought with it a celebration of the Materials Research Society's 20th anniversary. In addition to the technical symposia coordinated by meeting chairs Philippe M. Fauchet (University of Rochester), David B. Poker (Oak Ridge National Laboratory), and Alan I. Taub (Ford Research Laboratory), the meeting offered a glimpse into the history of MRS and the development of materials science over the past two decades. The meeting, held November 29 through December 3 and attracting an estimated 3,800 attendees, was embellished with a photo display showing the chronology of MRS events, plus introductory historical remarks kicking off some of the technical symposia.

Symposium AA, designated the Balluffi Fest, also celebrated past accomplishments. It was a tribute to the progress in understanding atomic-scale imperfections in honor of Robert W. Balluffi's exemplary career.

The meeting was also a time for look- ing into the materials research "crystal ball." A panel discussion in Symposium A, Materials Synthesis and Processing Using Ion Beams, looked at prospects for new commercial processes and applications of ion beams for cutting tools, aircraft parts, silicon-on-insulator (SOI) processing, and others.

In another session, Tom Seidel, chief scientist at Sematech, and Tadahiro Ohmi, Tohoku University, described the status of the semiconductor industry and where it's headed, including prospects for SOI technology and wide bandgap materials. Ohmi described the aim for human intelligence systems; current technology achieves the equivalent of $10^{3}$ neurons, still a far cry from the human brain's $10^{10}$ neurons.

A panel discussion during the Symposium on the Scientific Basis for Nuclear Waste Management examined the objectives and limitations of scientific studies for determining appropriate management of nuclear waste. Panelists acknowledged that there are diverse views about what scientific solution is optimum. They neared consensus, however, on the need to incorporate flexibility in a system, so the system can be altered based on subsequent research findings. Panelists were also of the opinion that the government's expectation of 10,000 -year predictions is a major impediment to the institution of any system.

Symposium I, Developing Materials Processes for Factories, addressed manufacturing issues in materials science. It was led off by NSF Director, John $\mathrm{H}$. Hopps, who spoke about the Clinton administration's role in manufacturing. Other sessions presented examples of process development in a variety of materials classes.

Biology continued its growing link with materials science. Bioelectronics, particularly bacteriorhodopsin, was the subject of an intense session. This material has properties that are highly favorable for applications such as optical data storage and holographic pattern recognition.

The first MRS symposium on New Materials for Advanced Solid State Lasers, Symposium $R$, revealed rapid progress over the past five years. Research has focused on the elements of miniaturization, cost reduction, and wavelength selectivity.

The diversity of topics in Symposium $Q$ on Organic Solid State Materials demonstrated the long-term significance and ever-changing nature of the field Liquid crystals are well-established commercially, while light-emitting organic polymer diodes are just emerging, yet both are potentially useful in commercial development of flat panel displays.

Characterization techniques have further been refined. New microscopy and spectroscopy techniques are directly revealing physical properties down to nanometer and molecular levels, and in some cases even below 1 angstrom. Noninvasive optical diagnostic techniques have been developed for monitoring materials and process properties.

Defects, interfaces, and phase transformations received attention in several symposia. Issues related to thin oxides for MOS devices, formation and properties of iron silicides, metal reactions with $\mathrm{Si}-\mathrm{Ge}$ alloys; and defect states common to a variety of amorphous materials as they recrystallize.

In the symposium on Superconductors, a particular emphasis on high-power applications of high-temperature superconductors revealed progress in creating longer wire lengths, higher current carrying capacity, and larger coils.

Other symposia covered fullerenes, electronic packaging, advanced semiconductors and heterostructures, complex fluids, disordered materials, non-oxide covalent ceramics, MOCVD, gas-phase surface chemistry, and high-temperature silicides and refractory alloys.

For highlights of the symposia, read the summaries on the following pages. More detailed information is available in the published proceedings.

\section{Plenary Session}

Hazel O'Leary, the Department of Energy Secretary, drew an overflowing crowd of about 800 people. She spoke about DOE's role in support of materials research, and how science and technology can be used as a strategic weapon in the new "economic war." See Material Matters, p. 7-13, in this issue for her plenary address. 


\section{NSF Undergraduate Materials Education Workshop}

A half-day workshop held during the 1993 MRS Fall Meeting gave NSF grantees a chance to report on progress made during their first year of support under the NSF Undergraduate Materials Education Initiative. Their projects, highlighted below, concerned integrated course and curriculum development at the advanced undergraduate levels in materials synthesis and processing.

Interactive discussion between the speakers and an audience of about 45 materials science and engineering researchers and educators raised issues primarily focused on: (1) requests for more details on laboratory and lecture course content; (2) how to accommodate additional laboratory and lecture courses into already overloaded curricula; (3) student response and faculty enthusiasm for this new venture; and (4) a timeline for the availability of materials developed.

- Arizona State University. Nicole Herbots (602-965-0581) and colleagues from five departments are developing and team-teaching a four-semester lecture, laboratory, case history sequence of courses focusing on materials processing issues related to electronic device fabrication. Examples include: crystal growth, epitaxial layer growth, chemical and physical vapor deposition, thermal oxide growth, powder synthesis, and characterization techniques. - lowa State University. Kristen P. Constant (515-294-3337) and colleagues are developing 11 flexible course modules (a booklet, videotape, and computer disk) on metal and ceramic powder processing, and processing aspects of glass and electronic materials. The 4- to 6week long modules can be used to update existing courses or to establish a new course. - Lehigh University. Kamil Klier (215-758-3470) and colleagues are developing a series of four integrated lecture-laboratory courses on nanostructure materials, leading to a BS/MS degree in chemical science. Ten-week student internships on research projects jointly supervised by Lehigh faculty and industrial scientists are under way during the summer period - MIT. Michael Rubner (617-253-4477) and colleagues have developed new, unified undergraduate, hands-on, and design-based laboratories to teach students how to manipulate and tailor the performance of a material through synthesis and processing, and to demonstrate that the underlying principles guiding this process are applicable to all classes of materials.

- Purdue University. Kevin Trumble (317-494-1204) and colleagues are developing a sequence of six new senior-level inorganic and organic materials processing laboratory courses covering deposition, solidification, powder, and deformation processing. A final processing design project with an open-ended "make it from scratch" approach allows students to further explore their particular interests.

- Wayne State University. Gregory Auner (313-577-3904) and colleagues are developing a new two-course lecture and laboratory sequence for senior undergraduates, which focuses on synthesis, processing, and in situ characterization techniques for advanced electronic and photonic materials and devices. The emphasis is on emerging technologies and hands-on laboratory experience. The program is guided by a committee composed of members from industry and academia.

Copies of the speakers' slides and an executive summary of their presentations are available from: Robert J. Reynik, Head: Office of Special Programs in Materials, Division of Materials Research, National Science Foundation, 4201 Wilson Blvd., Arlington, VA 22230. Tel. (703) 306-1814; fax (703) 306-0515. For additional information, you are also encouraged to contact the speakers at the phone numbers listed.

\section{Grass Roots Education}

Ken Eckelmeyer led a lunchtime session titled, "How Materials Scientists Vary the Properties of Engineering Materials by Controlling Atomic Bonding and Atomic Arrangement," for more than 50 chemistry students from Cambridge High School. Eckelmeyer explained the nature of atoms and orbitals, bonding atoms to form molecules like $\mathrm{CH}_{4}$, and how these molecules extend to form longchain polymers. The highlight of the session, as quoted by one student, was the "awesome liquid nitrogen," used to demonstrate property changes of a plastic hose when chilled.

An evening training session was held at MIT for about 35 MIT students who were involved in science activities in Cambridge Elementary Schools under the auspices of Cambridge School Volunteers, Inc. Eckelmeyer engaged the "volunteers in training" in participatory demonstrations as well.

\section{NSF Materials Education Initiatives and Coalitions}

During a workshop organized by Bob Reynik of NSF's Division of Materials Research, recipients of grants under the NSF Undergraduate Materials Education Initiative reported on the progress they had made during their first year of support. Information from the workshop has been collected and copied and is available from Reynick at the address listed in the summary of their reports which appears on this page. Additional information is also available from the workshop speakers, whose phone numbers are also listed in the summary.

J. Hren and John Russ organized a session on NSF Educational Coalitions for the Re-Engineering of Undergraduate Materials Education. Five people who are involved in these coalitions and who teach materials science to beginning undergraduate students described the work being done through their NSF coalitions. Many of the coalitions use computer-based learning to help students visualize difficult concepts, to access information, and to learn interactively on their own level. (See summary elsewhere in this report.)

\section{Society-Wide Colloquium}

A Society-Wide Colloquium coordinated by Rustum Roy addressed "Information, Its Nature, Sources, and Effective Use." Eugene Garfield, founder-president of The Institute for Scientific Information, described ways to access information in the literature, particularly through the ISI Science Citation Index and the more recently developed Materials Science Citation Index. Both citation-based databases, available on CD-ROM, are useful tools for navigating the archives. John Rodgers, National Research Council, Ottawa, followed with a presentation on "Data for Design: Databases on Materials and Their Utilization." Computer-stored databases compiled from data in the literature and materials models can be manipulated and used to see trends in data, to refine existing models, and to guide experimental design. A general discussion followed on the quality of literature itself, and ways to improve it.

\section{Awards}

After the Von Hippel Award was presented to Frederick Seitz, president emeritus of The Rockefeller University, Seitz talked about the important role that mathematician John von Neumann played in giving prominence to the discipline of materials science. The text of his talk can be found on p. 60-62 in this issue.

MRS Medalists, Wolfgang Krätschmer, professor at the Max-Planck-Institut für Kernphysik, and Donald R. Huffman, professor in the Department of Physics at the University of Arizona, presented special invited talks, "Fullerene Science and Astrophysics: A Fruitful Interaction" and " $\mathrm{C}_{60}$ and Other Fullerenes: What Are They Good For," respectively. Their talks were integrated into the symposium on 


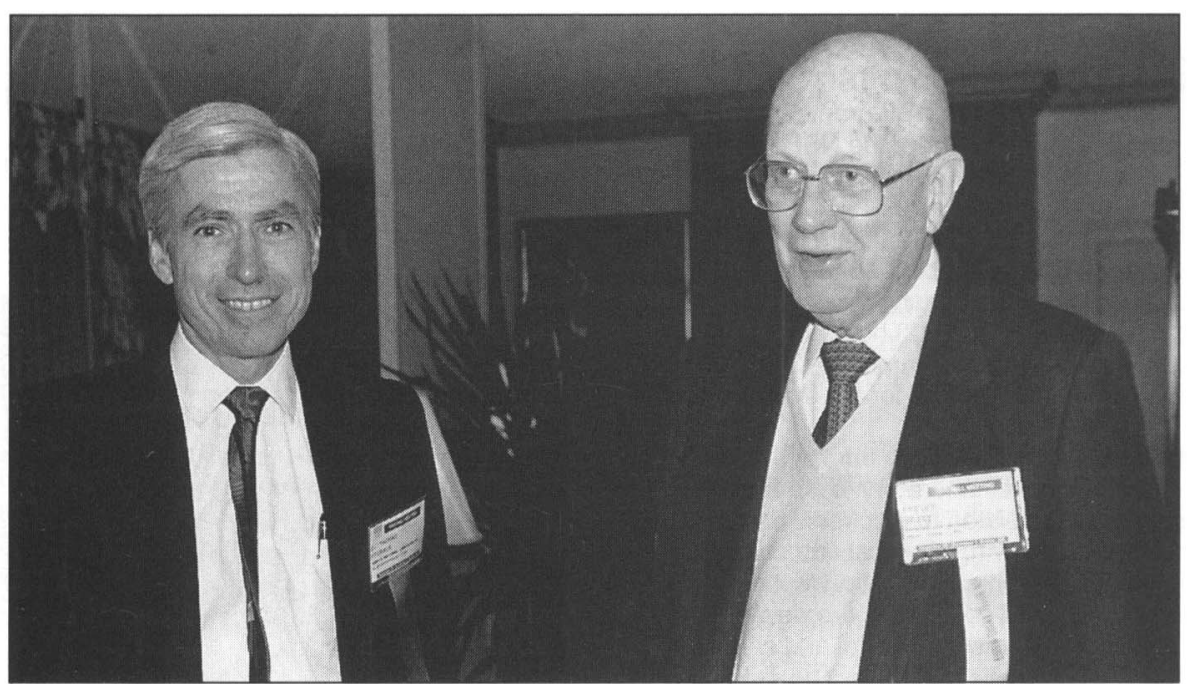

Frederick Seitz (right), President Emeritus of Rockefeller University and 1993 Von Hippel Award recipient, talks with 1993 MRS President Tom Picraux before the awards ceremony.

fullerenes, which also covered fullerenerelated structures such as buckyonions, spheroids, nanotubes, and endohedral metallofullerenes.

The Turnbull lectureship was awarded at the Fall Meeting to Morris Cohen from MIT. He gave some introductory remarks during the awards ceremony expressing his "long-standing admiration and respect for David Turnbull," the namesake of the award. Cohen will present his Turnbull lecture Wednesday, April 6 in the Presidio Room of the San Francisco Marriott Hotel, during the MRS Spring Meeting.

Graduate Student Awards were also presented during the awards ceremony to 12 recipients, who are listed elsewhere in this report.

\section{Balluffi Fest Celebrates Atomic-Scale Imperfections}

Atomic-Scale Imperfections in Materials: R.W. Balluffi Fest, Symposium AA, was held to honor Prof. Robert W. Balluffi (MIT). Balluffi has received many well-deserved honors for exemplary research in materials over his long and productive career, including the Von Hippel Award. The Symposium was organized by his students and colleagues D.N. Seidman (Northwestern Univ.), R.W. Siegel (Argonne Natl. Lab.), and P.D. Bristowe (MIT) on the occasion of Balluffi's upcoming 70th birthday in April 1994. Thirty invited scientific talks were presented by students, colleagues, and friends of Bob Balluffi over three

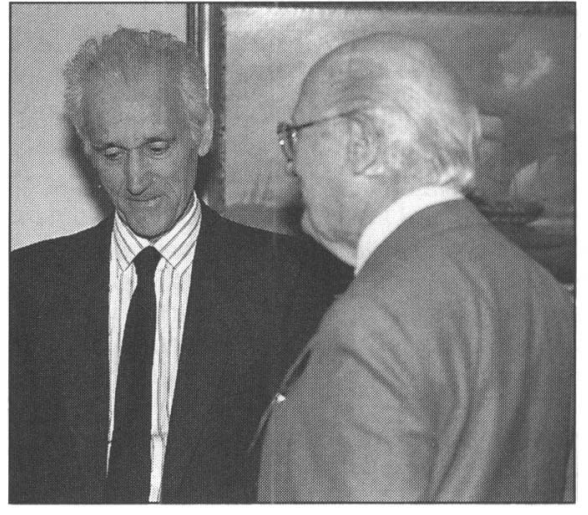

Robert W. Balluffi (left) speaks with Morris Cohen, 1993 Turnbull Lectureship recipient.

days to largely standing room only audiences. These excellent talks covered some new research directions in materials science, point defects, diffusion, and grain boundaries and interfaces, in which Balluffi has worked during his illustrious career at a variety of institutions. At the beginning of each day, a warm retrospective overview of Balluffi's activities at MIT, Sylvania, Columbia Univ., Univ. of Illinois, and Cornell Univ., was presented by his present and former colleagues $M$. Cohen (MIT), W.S. Owen (MIT), and M.C. Flemings (MIT). The spirit of these talks carried over to an excellent symposium dinner, generously hosted by the Department of Materials Science and
Engineering at the MIT Faculty Club, and to the historical and humorous after-dinner talk by Balluffi's long-time friend H.K. Birnbaum (Univ. of Illinois). The proceedings of the "Balluffi Fest" will be published in a special Festschrift issue of the international archival Journal of Physics and Chemistry of Solids in 1994.

\section{Panel Addresses Commercialization of Ion Beam Modification of Materials (See MRS Proceedings Volume 316)}

One focus of Symposium A, Materials Synthesis and Processing Using Ion Beams, was to better understand marketplace forces which impact commercialization of ion-beam processing and synthesis techniques. A panel was convened to discuss these issues. Reported activities by the U.S. Department of Defense in awarding a contract to install an ion implanter, expressly for improving the tribological properties of cutting tools and various aircraft parts, provided an optimistic prospect for commercialization of this technology. Also, information was provided on new machines at both Los Alamos and Sandia National Laboratories for modifying metals, which have spawned industrial collaborations with companies such as General Motors. Further commercialization is anticipated in microelectronics, where requirements for low-power devices are driving the industry toward a silicon-on-insulator starting material synthesized by SIMOX (separation by implantation of oxygen). The meeting provided clear evidence that there is substantial momentum to move many ion-beam technologies out of the laboratories and into production.

Research highlights of the meeting included innovations in nanostructuring of materials by ion implantation especially in the areas of optics and optoelectronics. Visible photoluminescence arising from quantum confinement effects in colloidal glasses were reported, as well as nonlinear optical responses in a host of implanted dielectrics. Other results provided insight into the role of impurities such as $\mathrm{O}$ and $\mathrm{F}$ in enhancing the photoluminescence yield of Er-implanted Si. Defect engineering is another area where important innovation is occurring. This is particularly true for SIMOX, where it was shown that appropriate manipulation of ion-induced defect profiles could markedly reduce the dislocation density in the material.

Symposium Support: Applied Materials, Ion Tech Inc., National Electrostatics Corporation, Nissan Electric Company Ltd., Oak Ridge National Laboratory, Varian/lon Implants Systems. 


\section{Connection Grows Between Atomistics and Thin Film Evolution (See MRS Proceedings Volume 317)}

As the use of STM becomes almost routine, we are directly seeing the connections between the atomistic details of growth and the final microstructure of films. The 160 papers presented in Symposium B, Mechanisms of Thin Film Evolution, spanned topics from basic single-atom processes to bulk film texture. Among several papers that started from atoms and moved up from there, J. Greene (Univ. of Illinois) used observations of initial adsorption of disilane to develop deposition techniques for single monolayers of Si and S.M. Gates (IBM) did this for dichlorosilane. Several key papers were presented on step rearrangements; M.G. Lagally (Univ. of Wisconsin) showed particularly beautiful data on $\mathrm{Si}$ MBE growth in the presence of hydrogen. A number of authors addressed the question of how step diffusion processes link to long-time roughening in crystal growth, with A.J. Pidduck (Defence Research Agency) in particular showing quantitative data linking local misorientation to diffusion lengths. New twists to the roles played by surface impurities were provided in a gorgeous study by $\mathrm{G}$. Comsa (IGV/KFA); in addition to other effects, impurities can selectively modify diffusion barriers at steps, with dramatic consequences for morphology. In a packed session on islanding, D.J. Srolovitz (Weizmann Institute) reviewed strain-driven morphological changes, and P.H. Fuoss (AT\&T) showed XRD data bringing out knowledge of steps in MOCVD in line with that in MBE. Several old conflicts on the evolution of islands and facets in $\mathrm{Ge} / \mathrm{Si}$ were resolved by $\mathrm{A}$. Sakai (NEC), who provided a definitive picture for island and defect evolution at different temperatures. The final link from the microscopic to the mesoscopic to the macroscopic came in the session on texturing of "thin" films, where J.C. Bilello (Univ. of Michigan) reported results for $0.1 \mathrm{~mm}$ films separated from the substrate and broken in an Instron machine.

Symposium Support: Denton Vacuum, EPI, Thermionics Laboratory Inc.

\section{Interface Control Critical for Microelectronics}

(See MRS Proceedings Volume 318)

Symposium $\mathrm{Ca}$, Interface Control of Electrical, Chemical, and Mechanical Properties, considered a wide range of materials issues from a variety of perspectives. Because interfaces are critical for the most demanding microelectronic applications, many papers focused on this area. For example, thin oxides remain an increasing problem as MOS devices shrink in size. There is increasing evidence of a qualitative deviation from bulk properties at the $\mathrm{Si} / \mathrm{SiO}_{2}$ interface. Substantial progress is being made on understanding how to make silicon surfaces clean and smooth for high-yield processes. Passivating film surfaces has become critical for copper metallization and remains difficult for GaAs. A lot of progress is being made in achieving good heteroepitaxy of SiGe on $\mathrm{Si}$ and more exotic compound semiconductors such as $\mathrm{CdTe}$ and GaAs and Si substrates. We saw evidence of the dramatic effects interfaces can have on the behavior of ferroelectrics, superconductors, and ceramics. Quite a lot has been learned in recent years about what determines the electrical behavior of metal/semiconductor contacts, but valid interpretation of contact resistance measurements remains challenging. Similarly, it is apparent that our understanding of Schottky barrier heights was inadequate and remains controversial. There is a growing appreciation of the important role that interfaces and the state of stress at the interfaces play in adhesion, heteroepitaxy, and composite materials. Experimental techniques (HRTEM, XPS, AFM, and high resolution LEED) are giving us a better picture of behavior at and below the monolayer level. However, understanding often has been advanced more by the use of phenomenological models than by first-principles calculations at the atomic level.

In a period of increasing global competition, it was exciting to have Japanese and U.S. sponsorship of this symposium, as well as a chance for constructive dialogue on materials issues from a multinational perspective. This was exemplified by the presentations and discussion on Thursday evening by T.E. Seidel from Sematech and T. Ohmi (Tohoku Univ.) on the future for materials in semiconducting technology.

Symposium Support: Air Products \& Chemicals, Fujitsu Laboratories, Hitachi Ltd., Mitsubishi Electric Corporation, NEC Corporation, Sematech, Texas Instruments.

\section{Defect-Interface Interactions Elucidated}

(See MRS Proceedings Volume 319)

Symposium $\mathrm{Cb}$, Defect-Interface Interactions, covered structure, kinetics, chemistry, and electronic behavior, from both theoretical and experimental viewpoints. The defects considered ranged from intrinsic point defects to dislocations to heterolayer structures.

Heterostructures were one area of particular interest. Several talks covered semiconductor heterostructures, but much of the research focused on other systems. Among these talks, M. Rühle (Max-Planck-Institut für Metallforschung) presented some of his group's work on metal/ceramic epitaxy, and R. Ramesh (Bellcore) gave an update on growth and performance of textured and epitaxial electronic oxide multilayers.

Kinetics and processing received substantial attention. Several talks dealt with the motion of point defects in and near interfaces. K.J. Jones (Univ. of Florida) demonstrated results of the use of dislocation loops as "detectors" for point defects, and L.C. Wang (Texas A\&M Univ.) explained how variations in chemistry affected the solid phase regrowth in metal/GaAs systems. P. Pirouz (Case Western Reserve Univ.) discussed the development of dislocation structures under conditions where misfit strains were time-dependent, and several other speakers also reported new aspects of the introduction and development of misfit dislocations in strained-layer systems. On a more macroscopic scale, J.T.H. deHossen (Univ. of Groningen) gave a view of the interactions of metal substrates with ceramic coatings during laser annealing.

A pair of sessions on grain boundary interactions with defects had a slight emphasis on metallic systems, including a presentation of in situ examination of dislocations interacting with grain boundaries, given by I.M. Robertson (Univ. of Illinois). Other materials systems were also well-represented, with major presentations of studies of grain boundary/dislocation interactions in ice (I. Baker, Dartmouth College), semiconductors (J. Thibault, CEA Grenoble), and ceramics, including superconductors (Y. Zhu, Brookhaven National Lab.).

Symposium Support: AMRAY Inc., JEOL USA Inc., Philips Electronic Instruments, Sandia National Laboratories, Topcon Inc.

Interfacing with Silicides, Germanides (See MRS Proceedings Volume 320)

Symposium D, Silicides, Germanides, and Their Interfaces, provided a concentrated look at metal silicides and germanides, including applications, formation, and the electronic properties of interfaces. Two areas which received considerably more attention than in past meetings were formation and properties of iron silicides and metal reactions with and contacts to $\mathrm{Si}_{1-x} \mathrm{Ge}_{x}$ alloys. Also of general interest were invited talks on silicide applications, the future of silicides in VLSI applications being particularly interesting.

Interest in $\mathrm{FeSi}_{2}$ stems from an earlierreported direct bandgap of approximately $0.8 \mathrm{eV}$ for the beta phase, suggesting the possibility of Group-IV-compatible 
optoelectronic devices operating at fiberoptic wavelengths. Most effort to date has been directed toward attempts to grow single-crystal thin films of $\mathrm{FeSi}_{2}$ on $\mathrm{Si}$ substrates. Only limited success has been achieved due to the noncubic structure of the beta phase and the existence of alpha and gamma phases. The most significant recent experimental work suggests that the bandgap of the beta phase is actually indirect, with a direct transition at slightly larger energy, though there is not broad consensus on the nature of the gap.

Various devices demonstrated in recent years utilize $\mathrm{Si}_{1-x} \mathrm{Ge}_{x}$ alloys, some of which could be integrated in VLSI technology to allow improved performance. As a result, understanding ohmic and Schottky contacts to $\mathrm{Si}_{1-x} \mathrm{Ge}_{x}$ alloys is of interest, and a number of papers addressed this issue. Several papers dealt with the reaction of $\mathrm{Co}$ or $\mathrm{Ti}$ with $\mathrm{Si}_{1-x}$ Gex alloy layers. A uniform metal/silicon/germanium alloy is desired, rather than segregated silicide and germanide grains. Studies are also being conducted on Schottky barrier heights to $\mathrm{Si}_{1-x} \mathrm{Ge}_{x}$ alloys, with the barrier height generally observed to be intermediate to metal/silicon and metal/germanium values.

The future of silicides as shallow contacts and interconnects for deep submicron CMOS technology was a topic of some debate. S.P. Murarka (Rensselaer Polytechnic Institute) feels that $\mathrm{CoSi}_{2}$ is the most attractive silicide for gate lengths below $0.25 \mu \mathrm{m}$ due to a combination of features including low resistivity, and good thermal and chemical stability. L.A. Clevenger (IBM), on the other hand, feels that $\mathrm{TiSi}_{2}$ will remain dominant for the foreseeable future due to its slightly better thermal stability and its widespread present use. One problem remaining for $\mathrm{TiSi}_{2}$ is its tendency to agglomerate for narrower line widths.

Symposium Support: EPI Chorus Division, Fisons NG Instruments, Intevac, Jet Propulsion Laboratory, Siemens AG.

\section{Amorphous Ceramics, Metals, Polymers, Semiconductors Show Common Recrystallization Behavior (See MRS Proceedings Volume 321)}

Symposium E, Crystallization and Related Phenomena in Amorphous Materials: Ceramics, Metals, Polymers, and Semiconductors, was designed to be highly interdisciplinary and enhance cross-fertilization of ideas and techniques between researchers working with different kinds of materials. In addition to significant contributions from the traditionally strong base of work on semiconductors and electronic materials, the sympo- sium attracted significant participation from the polymer, geological materials, metals, and ceramics communities.

One theme that surfaced repeatedly in the symposium was the defect structure of the amorphous state, since these defects control the relaxation of amorphous material as well as the nucleation and growth kinetics of the crystalline phase. The symposium began with an overview by D. Turnbull (Harvard Univ.) honoring MRS's 20th anniversary. This was followed by oral sessions on the structure of glasses and relaxation processes. Of particular note were presentations concentrating on new insights provided by structural and thermodynamic characterization techniques such as calorimetry (A. Navrotsky, Princeton Univ.), NMR (J.F. Stebbins, Stanford Univ.), light scattering (J. Kieffer, Univ. of Illinois), filtered electron diffraction (L.W. Hobbs, MIT), liquid chromatography (B.C. Sales, Oak Ridge Natl. Lab.), and positron annihilation. These insights into amorphous structure provided the foundation for following sessions on crystal nucleation and growth. A.L. Greer (Cambridge Univ.) reviewed transient nucleation processes using lithium disilicate as a model system. D.A. Smith (Stevens Inst. of Tech.) described in situ TEM annealing studies of $\mathrm{CoSi}_{2}$ films that separately establish the nucleation kinetics and the growth kinetics in an Avrami-type analysis. Several contributions on solid-state amorphization had a common theme, the structural/compositional instability responsible for the collapse of a crystalline lattice. This theme was also revisited in the session on ion-beam-driven amorphization. The session on polymer crystallization generated lively discussion of the morphological development of spherulites. Yet unresolved is the important question of when and how interlamellar structure develops. A joint session with Symposium A, Materials Synthesis and Processing Using Ion Beams, addressed advances in the understanding of ion-beam assisted crystallization. H.A. Atwater (Caltech) illustrated how high-energy ion beams can affect the kinetics of crystal nucleation and growth. Applications of these ideas apply to producing photoluminescent silicon nanocrystal microstructures in amorphous $\mathrm{SiO}_{2}$. Following talks addressed the solid phase epitaxial growth kinetics of silicon and related alloys as a function of composition (R.G. Elliman, Australian Nat. Univ.), orientation (J.S. Custer, Sandia Natl. Labs.), and pressure (M.J. Aziz, Harvard Univ.). Together these place severe constraints on atomistic models of amorphous/crystal interfacial evolution in these covalent solids. Other papers discussed the development of microstructure during the crystallization of amorphous silicon for thin-film transistor applications.

It is clear that the defect structure of amorphous materials controls their kinetic behavior. This symposium showed that great progress is being made toward defining and controlling such defects. This foundation is necessary for the intelligent control of nicrostructural development in glasses and viscous liquids and is common to all materials classes.

Symposium Support: Allied Signal Inc., Hoechst Celanese Corporation, Oak Ridge National Laboratory.

\section{Enhanced Low and High Temperature Mechanical Properties Produced in High Temperature Structural Materials (See MRS Proceedings Volume 322)}

The four-day Symposium on High Temperature Silicides and Refractory Alloys, Symposium F, featured presentations on synthesis, processing, mechanical properties, oxidation behavior and application of both monolithic and composite materials. The symposium content was split between silicides and refractory alloys.

Separate overviews of recent developments in silicides and refractory alloys were presented by J.J. Petrovic (Los Alamos Natl. Lab.) and T.G. Nieh (Lawrence Livermore Natl. Lab.), respectively. There was a strong emphasis on recent work on $\mathrm{MoSi}_{2}$, where significant developments in both its high and low temperature mechanical properties were reported. Separate papers by Y. Umakoshi (Osaka Univ.), S. Maloy (Los Alamos Natl. Lab.), and R. Gibala (Univ. of Michigan) described progress in the understanding of plastic deformation. Improvements in the creep resistance of MoSi2-based materials were reported by K. Sadananda (Naval Research Lab.) and $\mathrm{S}$. Suresh (MIT). The meeting also provided some insight into the present level of understanding and technology based on monolithic refractory alloys. Areas for future applications of present commercial monolithic refractory alloys were presented, along with potential new applications for composite materials, such as microlaminates, hot pressed structures, directionally solidified structures, and mill products. For example, R. Castro (Los Alamos Natl. Lab.) reported on the fabrication of prototype $\mathrm{MoSi}_{2}$ composite burner components. 
Symposium Support: General Electric Company, Office of Naval Research, Osram Sylvania Inc.

\section{Researchers Reflect on Fullerene Progress}

Fullerenes and Related Materials, Symposium G, began with a brief history of the fullerene field and its role in the MRS Fall Meeting, where the first results in this new field exploded on the scene three years ago. The 1993 Fall Meeting presented an opportunity to reflect on how the field has developed and where it may be headed. Some speakers addressed the general question, "What are $C_{60}$ and other fullerenes good for?" Among applications mentioned were lubricants, storage batteries, diamond film growth, hydrogen storage, catalysis, ink additives, superconductors, and rocket propulsions. Reference was also made to applications of fullerenes as antiviral agents.

One group reported that fullerenes “....work well as a lubricant in low humidity vacuums and may be a candidate for precision lubrication uses in space." The loosely bound fullerene molecules form clusters resembling blackberries. When the pressure and friction grew great enough to collapse these clusters, the individual spherical molecules continued to provide lubrication.

W. Krätschmer (Max-Planck-Institut für Kernphysik) and D.R. Huffman (Univ. of Arizona), the first to produce macroscopic quantities of fullerenes and to demonstrate a new form of crystalline carbon, presented their MRS Medal speeches during this symposium and underlined the fruitful interaction of fullerene science and astrophysics. Although it appears unlikely that the presence of $C_{60}$ in space is responsible for the unidentified interstellar absorption at $220 \mathrm{~nm}$, higher fullerenes and "buckyonions" might account for some of these features. Buckyonions as large as $500 \AA$ diameter ( 70 spherical shells) were reported. Further search of the discharge soot, "the mother of all fullerenes," was encouraged for other carbon-based molecules, especially small carbon-hydrogen radical clusters. It is ironic that although small fullerenes are apparently not responsible for the unidentified absorption features, the further development of the fullerene field has produced new carbonaceous material which may in fact account for the mysterious interstellar medium.

Continued characterization and improvement of the Krätschmer-Huffman fullerene generation technique was prescribed, especially methods for continu- ous generation of large amounts of fullerenes without interruption for reloading the graphite rods. Combustion synthesis of fullerenes in a premixed flame produced "soot" with 20 to $30 \%$ fullerene. The $\mathrm{C}_{60} / \mathrm{C}_{70}$ ratio could be altered by varying the flame conditions. Techniques presented included a method for the vapor phase gradient separation and purification of $\mathrm{C}_{60}$, a metalloporphyrinbased stationary phase preparative column, and a method for chromatographic separation of "giant" fullerenes.

Several groups reported on structural and physical properties of carbon nanotubes. Theoretical considerations predict that the electrical conductivity of the nanotubes depends on the chiral "pitch" of the helical nanotubes (achiral tubes are metals and helical structures are semiconductors). Single crystals of copper were reported to be encapsulated in buckytube derivatives.

The first Raman spectrum of nanotubes showed that the four intense Raman lines were remarkably insensitive to the diameter of the buckytubes. The most intense feature was split into two lines $\left(1591 \mathrm{~cm}^{-1}\right.$ and $1569 \mathrm{~cm}^{-1}$ ) as a result of the right-left helicity of the chiral nanotubes.

Laser ionization of fullerenes exhibits an unusual "delayed" ionization in which electrons are emitted from the graphite spheres long after (microseconds) pulsed laser excitation. This unusual behavior is generally ascribed to thermionic emission (i.e., the laser heats the graphite ball to a temperature sufficient to boil off electrons), but an alternative interpretation described involves the simultaneous excitation of as many as four Frenkel excitons on one $\mathrm{C}_{60}$ molecule. Delayed ionization thus results from multiple exciton annihilation.

Many papers dealt with the interaction of fullerenes with surfaces and their properties as multilayers and as superlattices. The mechanism of superconductivity was examined, and the first rare earth $(\mathrm{Yb})$ doped fullerene superconductor was reported $\left(T_{c}=5.7 \mathrm{~K}\right)$. A new synthesis route using thermal decomposition of azides was shown to give samples with high shielding characteristics. A theoretical description of a $\mathrm{C}_{60}$-graphite intercalation compound doped with potassium exhibited a high density of states at the Fermi level and offers promise as a high$T_{c}$ superconductor.

Fullerene-related materials such as buckyonions (concentric arrangement of fullerenes), spheroids (spherical particles), nanotubes, and endohedral metallofullerenes have gained special interest.
These materials are considered "fullerene-related," but their formation, structure, and electronic/solid state properties are completely different from the socalled fullerenes.

D. Ugarte (Ecole Polytechnique Fédérale de Lausanne) talked about buckyonions which are generated with a remarkable spherical shape as a result of the coalescence of nanometer scale carbon particles under electron beam irradiation. He showed a video of the transformation of the carbon particles to buckyonions. Another important development discussed was the successful characterization of endohedral metallofullerenes. Researchers reported the isolation and characterization of scandium $\left(\mathrm{Sc}_{2} @ \mathrm{C}_{82}\right.$, $\left.\mathrm{Sc}_{3} @ \mathrm{C}_{82}\right)$ and lanthanum $\left(\mathrm{La} @ \mathrm{C}_{82}\right)$ fullerenes. Scanning tunneling microscopy (STM) of $\mathrm{Sc}_{2} @ \mathrm{C}_{82}$ deposited on the $\mathrm{Si}$ (100) $2 \times 1$ clean surface indicated an approximately spherical structure of $\mathrm{Sc}_{\mathrm{C}} \mathrm{C}_{82}$ and a small bandgap compared with those of other fullerenes, indicating the possibility of high electrical conductivity. The STM and TEM results showed that the metal atoms are indeed trapped within the carbon cage, confirming previous studies.

Symposium Support: COMSTOCK, Exxon Research and Engineering Company, Martin Marietta Energy Systems, NEC Corporation, Office of Naval Research, R-DEC Company Ltd., Science Laboratories Inc., SES Research, Vacuum Metallurgical Company.

\section{High-Temperature Superconductors Display Their Power}

Symposium H, Superconductivity: Materials and Properties, opened with J.G. Daley (U.S. Dept. of Energy) reviewing potential high power applications of high-temperature superconductors (HTS) and describing three new DOE Strategic Partners Initiatives in motors, generators, and fault current limiters. He, and subsequent industrial speakers, reported improved values for wire lengths and current carrying capacities and larger coils. The continual improvements bode well for practical HTS conductors and devices.

L.N. Bulaevskii (Los Alamos Natl. Lab.) and D.C. Larbalestier (Univ. of Wisconsin) gave stimulating talks on the key issue of trans-grain boundary current conduction in HTS materials. C.W. (Paul) Chu (Univ. of Houston) reviewed the fabrication and superconducting characteristics of the recently discovered $\mathrm{Hg}-\mathrm{Ba}-\mathrm{Ca}$ $\mathrm{Cu}-\mathrm{O}$ compounds.

Discussing the vortex lattice phase change, D.E. Farrell (Case Western Reserve Univ.) made a clear distinction 


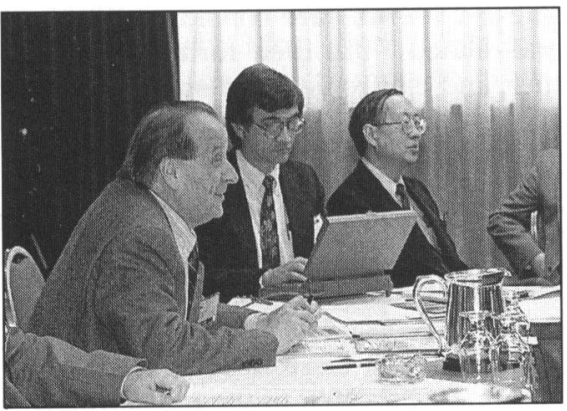

The International Union of Materials Research Societies General Assembly meets during the MRS Fall Meeting. IUMRS officers (lett to right): President Paul Siffert, Secretary Rodney C. Ewing, and Immediate Past President and General Secretary, R.P.H. Chang.

between the irreversibility line and a melting transition of the flux line vortex lattice in the layered HTS materials. K.H. Fischer (Jülich) covered the theory of the vortex lattice in layered materials. H.A. Mook (Oak Ridge Natl. Lab.) presented neutron diffraction evidence of one or two structural transitions of the flux line lattices in $\mathrm{YBa}_{2} \mathrm{Cu}_{3} \mathrm{O}_{7-x}$ and $\mathrm{Bi}_{x} \mathrm{Sr}_{2} \mathrm{CaCu}_{2}$. $\mathrm{O}_{8+x}$ crystals.

The closing sessions of the symposium were devoted to thin film and electronic applications of HTS, where steady progress toward devices is apparent. D.K. Christen (Oak Ridge Natl. Lab.) reported naturally occurring columnar defects observed in thin films of YBCO grown on miscut substrates and related these defects to the high current density in YBCO thin films. S. Okayama (FED) described the large-scale national project sponsored by MITI in Japan, on HTS 3terminal devices in which various device ideas are investigated by eight industrial companies. F. Pattern (ARPA) covered projects on multichip modules (MCM) the agency is sponsoring. Details on progress were reported by Neocera, Conductus, and STI. Finally, recent work by John Clarke's group at UC-Berkeley on a HTS SQUID magnetometer with a directly coupled input coil which showed record low noises was quoted by several speakers as a major advance in HTS electronic devices.

Symposium Support: Argonne National Laboratory, Los Alamos National Laboratory, Neocera Inc., Oak Ridge National Laboratory.

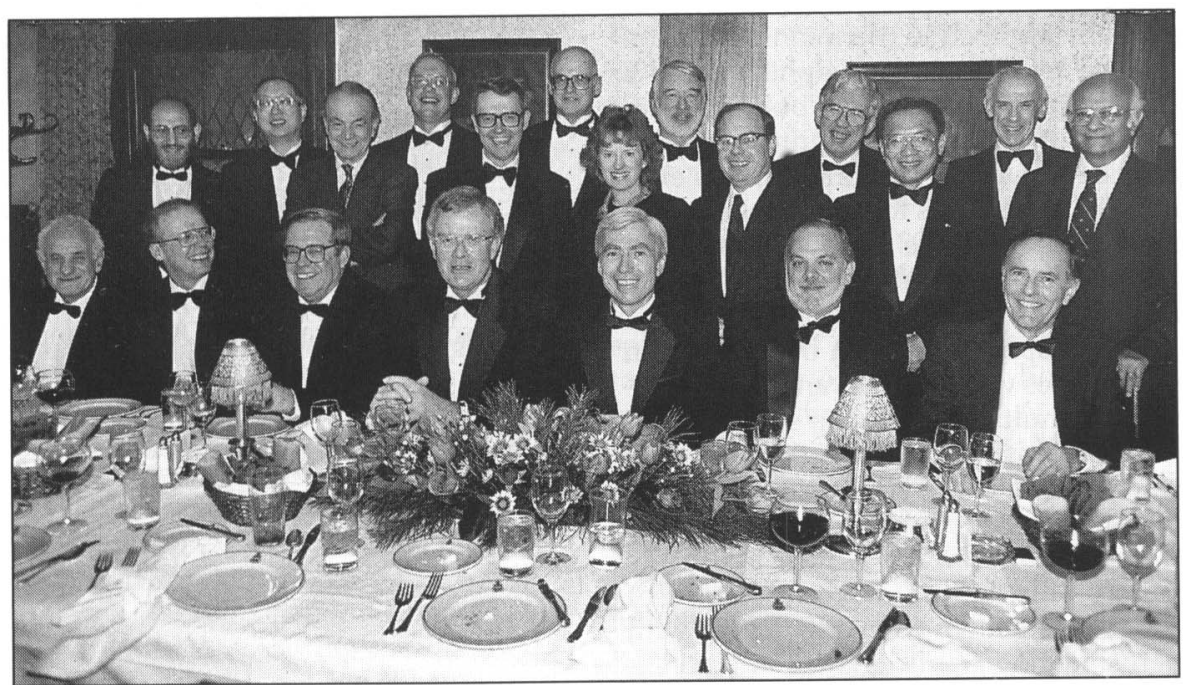

Former presidents and founders of MRS gather at the founder's dinner to celebrate the 20th anniversary of MRS. Front row left to right (year of presidency is listed in parenthesis): Richard S. Stein (founding Councillor), G. Slade Cargill III (1992), C. W. White (1984) John M. Poate (1980), S. Thomas Picraux (1993), Russell R. Chianelli (1990), Robert A. Huggins (founding Councillor). Back row left to right: Elton N. Kaufmann (1985), R.P.H. Chang (1989), Harry C. Gatos (1973-1976), Harry J. Leamy (1983), Mark Myers (founding secretary), Clyde J.M. Northrup, Jr. (1982), Kathleen C. Taylor (1987), Kenneth A. Jackson (1978), Gordon E. Pike (1986), Robert A. Laudise (founding Councillor), King Ning Tu (1981), John E.E. Baglin (1988), Rustum Roy (1977).
Manufacturing Seen As Integral Part of Materials Development

Symposium I, Developing Materials Processes for Manufacturing, was a bridging experiment. MRS meetings have traditionally been strong in scientific research, and this symposia aimed to link research to the practical end of manufacturing.

The highlight of the symposium was the excellent keynote address by John $\mathrm{H}$. Hopps, director, Division of Materials Research, National Science Foundation. Hopps noted the proactive stance taken by the Clinton administration with their advanced manufacturing initiative. This is reflected in increased funding to NIST, DOD, NSF and NASA for manufacturing research.

The following talks were devoted to measures of performance and factory modeling. These included talks from the universities (J.P. Clark and P. Losleben of MIT and Stanford Univ., respectively) and the practical applications of the basic ideas expounded by R.J. Baseman (IBM), J.K. Kibarian (PDF Solutions), and T.S. Babin (Motorola). The underlying issue was how to efficiently execute a process on the manufacturing floor without sacrificing quality.

Subsequent sessions focused on several specific examples but also covered an extraordinary variety of topics. R.G. Menzies (GE) discussed implementation of new materials in aircraft engines. $\mathrm{N}$. DeCristofaro (Allied Signal) spoke about amorphous metal tape manufacture. B.A. Zeitlin (Intermagnetics General) focused on the manufacture of superconductors and the lessons learned in taking the technology from the lab to the factory floor. D.A. Wheeler (Howmet) talked on metal casting technology. Another set of talks illuminated manufacturing examples in electronic applications, such as ULSI Si circuits, ceramic packaging, cleaning, and quality control.

Symposium Support: General Electric, IBM, National Semiconductor.

\section{Computer Modeling, Environmental Concerns Enter Electronic Packaging Agenda}

\section{(See MRS Proceedings Volume 323)}

The 7th MRS symposium on Electronic Packaging Materials Science, Symposium $\mathrm{J}$, was very well attended. A total of 61 oral presentations drew audiences ranging from 50 to 100 . This year's program focused on five specific areas: low-cost high-performance packages, deposition and durability, packaging materials and processes, mechanical testing and acceler- 


\section{NSF Educational Coalitions}

A special program under the National Science Foundation's Directorate of Engineering Education currently supports about eight coalitions related to engineering education. The purpose of the coalitions, with up to eight schools each, is to take a new look at engineering education from the beginning in all its aspects. The idea is to integrate the disciplines and look at problems as a whole rather than as a single-discipline problem.

Representatives of some of these coalitions described their programs at a special session held during the 1993 MRS Fall Meeting. In exchanging information, the participants discovered complementary aspects of their individual projects, and during informal discussions decided to share modules, materials, and other results.

The substantive aim is a series of topical modules on CD-ROM comprehensively covering materials science. Each module would be centered on a basic phenomenon or basic law and could be embellished by examples, applications, simulations, clips of experiments, etc. Topics would be treated at levels suitable for teaching high school to graduate school.

Highlights of the presentations are as follows:

- John Russ, North Carolina State University and R.G. Kander, Virginia Polytechnic Institute and State University, talked about the SUCCEED coalition. Russ described methods of supplementing verbal lectures with combinations of computer graphics, simulations, and video recordings of lab experiments to help meet the needs of students who learn better visually. Kander is involved in a project to enhance the freshman chemistry curriculum by using advanced computer visualization technology as a teaching aid. Difficult topics, but ones most important for further studies (crystallography, phase diagrams, Arrhenius behavior, dislocation motion, and mechanical testing) were developed using interactive teaching graphics.

- Gretchen Kalonji from the University of Washington is involved with the ECSEL Coalition, Re-Thinking Introductory Materials Science Education. In this program, introductory courses are design-based, work is cooperative, and grading is based on student journals rather than traditional testing. Students are involved in curriculum development and evaluation, and some students even act as undergraduate consultants, helping students in the introductory class.

- Mark R. De Guire, Case Western Reserve University, is involved in the Gateway Coalition, which, as one of its objectives, aims to expand the use of the university's Electronic Learning Environment in undergraduate engineering courses. It involves a hypermedia tutorial/study guide, an electronic bulletin board for the course, and multimedia computer presentations for a freshman engineering course.

- Dave Martin described NEEDS activities at lowa State University as part of the SYNTHESIS Coalition. NEEDS, the National Engineering Education Delivery System, is, in part, an electronic library designed to support engineering education. The program offers access to materials physically dispersed across many sites. Searches are done electronically via Internet, and users can obtain courseware modules, raw data, and computer tools.

- Robert W. Hendricks at Virginia Polytechnic Institute and State University described an Integrated Program in Engineering Communication. The program integrates oral, written, and graphical communication skills in the Materials Science and Engineering Department. Students learn writing and other presentation skills within the regular curriculum, instead of in separate courses.

For more information, contact: J. Hren and J. Russ, Materials Science and Engineering, North Carolina State University, Raleigh, NC 27695-7907.

Phone: Hren (919) 515-3568; Russ (919) 515-3328; fax (919) 515-7724.

E-mail: jhren@mte.ncsu.edu or russ @mte.ncsu.edu

ated testing, and supercomputer applications in materials science. The symposium opened with an authoritative overview of the current state of optoelectronic packaging by H.F. Lockwood from The Lockwood Group. D.B. Wrisley, Jr. (AMP Inc.) reviewed recent developments and trends in the development of high density flex connectors. W.T. LaFontaine (IBM) gave an excellent overview of high-performance PC-board technology, clearly outlining areas in which materials scientists can make vital contributions.

One of the most popular presentations was a talk by J.H. Harris (Carborundum) describing comprehensive experimental and theoretical investigations of the oxygen-related defects in AlN ceramics, leading to a fundamental quantitative understanding of its effect on the thermal conduction of this technologically important material.

Another of many highlights was an overview of current issues related to environmentally friendly materials and processes by J.M. Shaw (IBM) discussing the advances needed in materials science to keep abreast of public concern and legislation. This was followed by presentations on ongoing research to meet such needs.

Finally, there was a collection of talks on large-scale computer-based modeling and simulation of materials phenomena. U. Landman (Georgia Tech) showed numerous examples including thin film lubrication, nanotribology, and laser annealing and D. Taylor (Cornell Univ.) described the use of parallel computing for problems in orthopedic biomechanics. The latter field is complicated by complex geometries and nonhomogenous materials properties; human bone is an active material with properties that change with applied load and time.

Symposium Support: Amoco Ultradel Microelectronic Coatings, The Dow Chemical Company, IBM Endicott, IBM T.J. Watson Research Center, OCG Microelectronic Materials Inc.

\section{Optical Diagnostic Techniques Widely Applied to Monitor Materials and Processing \\ (See MRS Proceedings Volume 324)}

In the past decade there have been significant advances in the area of device fabrication. These advances were made possible by improvements in growth and processing technologies. Further improvements in device fabrication are expected to come from increased monitoring of device and materials properties during and after fabrication. Symposium K, Diagnostic Techniques for Semiconductor Materials Processing, featured various aspects of both device processing and process diagnostics. The process areas in which work was discussed included materials growth, etching, and device fabrication. Diagnostic techniques which were considered fell into two classes: invasive and non-invasive. The consensus of the symposium was that it is important to monitor both materials and process properties.

Optical characterization techniques were the most widely applied characterization tools used in both materials and process monitoring. Techniques such as reflectance difference, ellipsometry, reflectance, absorption, light scattering, photoreflectance, Raman scattering and thermal wave modulated reflectance were shown to be powerful probes of various materials properties. The materials properties that were probed included surface stoichiometry and morphology, etch damage, Fermi-level pinning position, and thin film properties such as thickness, alloy content, and interfacial roughness. Real-time diagnostics such as ellipsometry and reflectance difference were shown to be sensitive tools of materials properties during processing. These techniques promise sophisticated feedback control of materials growth. 


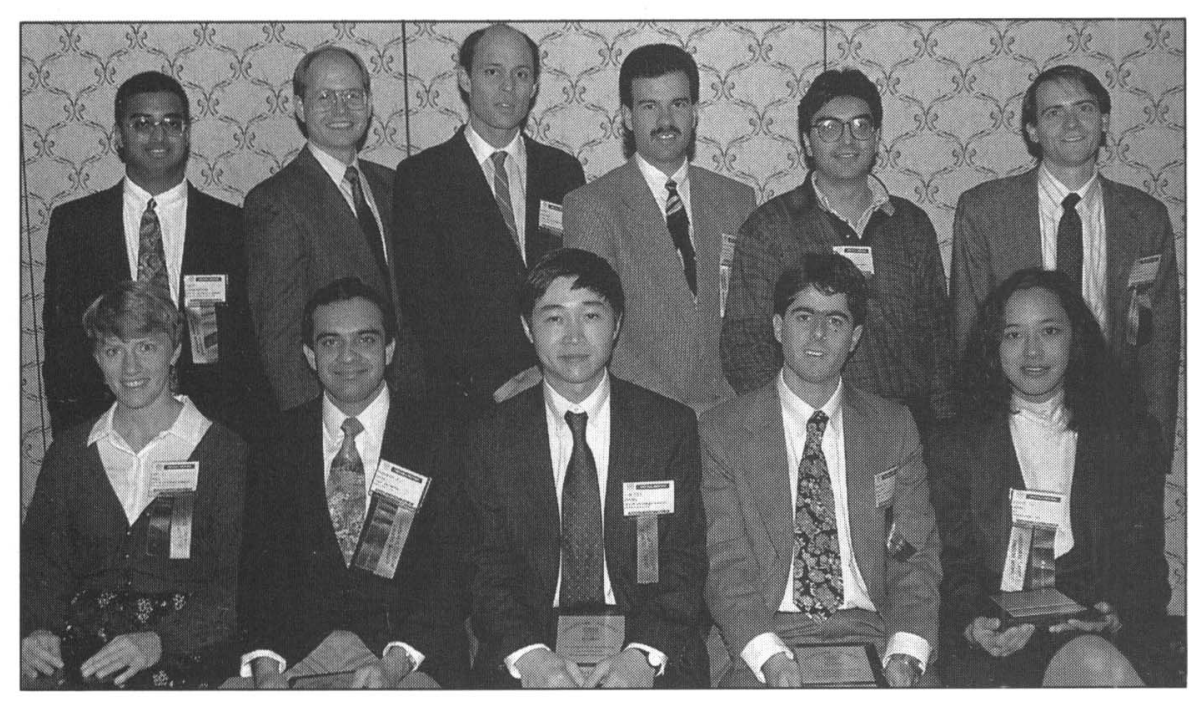

Of the 30 Graduate Student Award Finalists who were authors or co-authors of papers at
1993 MRS Fall Meeting and who participated in a special student presentation session,
12 received additional recognition for "outstanding performance in the conduct of
research." For a complete list of finalists, see the November 1993 MRS Bulletin p. 77-78

Graduate Student Award Recipients at the 1993 MRS Fall Meeting. (Seated, left to right): Amy J. Moll, Pushkar P. Apte, Jun Fei Zheng, David A. Muller, Joyce Y. Wong. (standing, left to right): Ravi Viswanathan, Glen T. Visscher, Harry Edelman, Christopher M. Rouleau, Taner Yildirim, John P. Sullivan. Not in the photo is Ahmed R. El-Ghannam.

In the area of process diagnostics, many techniques such as Langmuir probe, optical emission, mass spectrometry, IR reflection and absorption were shown to be powerful tools of process parameters including reactive species concentrations, reaction products, and residual gases in chamber. Once again, optical techniques were favored because of their non-invasive nature.

In summary, there is great interest in the development of diagnostic techniques for device fabrication. The application of diagnostic tools utilized in research to manufacturing environments was an underlying theme in the papers. As the research interest in this area grows, further and more exciting developments are expected in integrating processing and process diagnostics.

Symposium Support: ASTeX, Digital Instruments, MKS instruments, Naval Research Laboratory, Office of Naval Research.

\section{Defects Central to Performance of Quantum Wells, Superlattices} (See MRS Proceedings Volume 325)

Symposium L, Defects in Advanced Semiconductors: Physics and Applications, focused on semiconductor quantum wells, superlattices, and bulk materi- als grown by various techniques. The symposium consisted of 78 presentations with papers originating in 20 countries led by the United States, Germany, France, Japan, Sweden, and the United Kingdom. It brought together researchers from the areas of defects in low dimensional systems in semiconductors, defects in bulk materials, and defect engineering in semiconductors.

Defect characterization and identification and the influence of defects on material properties and device performance are major subjects in physics and applications of semiconductors. This symposium focused on defects in advanced semiconductors, specifically quantum wells, superlattices, and heterostructures. For example, one session dealt with defects in type I and II superlattices based on III-V semiconductors such as GaAs/AlGaAs multiple quantum wells (MQWs). Some of the topics covered were optical spectroscopy of defects in GaAs/AlGaAs MQWs, defect injection and diffusion in heterostructures, and impurity effects on the electronic states in quantum wires and quantum dots. Another session covered defects and impurities in bulk and epitaxial InP and related compounds, for example, the semi-insulating behavior of undoped InP.

$\mathrm{SiGe} / \mathrm{Si}$ quantum wells and heterostructures have gained increasing interest due to their applications in electronic and electrooptic devices. Defects, dislocation distribution, and doping in these heterostructures was discussed. Doping engineering is an interesting subject in the field of electronic devices such as heterojunction bipolar transistors (HBTs). Thus, doped layers for HBT applications such as InGaAs were a point of discussion. Control and incorporation of impurities such as $\mathrm{O}, \mathrm{H}, \mathrm{Zn}, \mathrm{Cd}$, rare earth impurities, and impurity complexes in III-V semiconductors were discussed in another session. In addition, during a joint session with Symposium M, Growth, Processing, and Characterization of Semiconductor Heterostructures, speakers presented results on ordering and controlling semiconductor alloys and superlattices.

Low temperature grown (LTG) GaAs has recently attracted the attention of many researchers in the field of defects in semiconductors. This is partly because LTG GaAs contains a large concentration of arsenic-related defects. The electrical and optical properties of LTG GaAs have been the subject of various investigation in recent years, and one session addresssed defects, stoichiometry, and precipitates in these materials.

Symposium Support: Air Force Office of Scientific Research.

\section{Light Shed on Visible-Range Optoelectronics and Quantum Structures}

(See MRS Proceedings Volume 326)

Symposium M, Growth, Processing, and Characterization of Semiconductor Heterostructures, included joint sessions with Symposium L (Defects in Advanced Semiconductors: Physics and Applications) and Symposium K (Diagnostic Techniques for Semiconductor Materials Processing).

The symposium covered a wide selection of topics in III-V, II-VI and group IV semiconductors. Two particularly popular themes were (1) visible-wavelength optoelectronic materials and devices and (2) quantum wells, wires and dots. The visible-wavelength materials centered around the GaInP-based materials for red applications, and ZnSe-based materials for blue applications. D.P. Bour (Xerox PARC) reported on the growth of edgeemitting quantum well laser diodes with threshold current densities of less than $200 \mathrm{~A} / \mathrm{cm}^{2}$ at wavelengths of $660 \mathrm{~nm}$, and higher threshold devices extending into the $610 \mathrm{~nm}$ band. R.P. Schneider Jr. and 
co-workers from Sandia National Laboratories reported on AlGaAs/AlInP materials for vertical cavity surface emitting red lasers. Numerous papers covered epitaxial growth on structured substrates for the construction of quantum wires. Growth on v-grooved substrates was the topic of several papers. A particularly elegant approach to the growth of quantum wires and dots was reported by L.N. Pfeiffer and co-workers of AT\&T Bell Laboratories. This group used the technique of growth on cleaved edges of conventional superlattices to produce quantum size effects and quantum wire lasing action.

Symposium Support: Army Research Office, EPI, Fisons NG Instruments, Instruments SA, Intevac, North Eastern Analytical Corporation, Sumitomo Electric USA Inc.

\section{Non-Oxide Ceramics Perform for Electronic and Structural Applications (See MRS Proceedings Volume 327)}

Covalent Ceramics II: Non-Oxides, Symposium N, follows the first symposium on this topic held at the 1990 Fall Meeting. Approximately 80 presentations and posters described the processing and properties of bulk (including composite) and thin-film sulfides, selenides, carbides, and nitrides for electronic, aerospace, and structural applications. Several talks briefly described here span the range of materials, processing technologies, and applications presented at the meeting.

A.N. MacInnes (Gallia, Inc.) described chemical vapor deposition (CVD) of cubic GaS from an organometallic gallium sulfide complex. The structure of the cubic tetramer is retained to produce a phase of $\mathrm{GaS}$ that is not obtainable by any other processing technique. The GaS has a high bandgap (ca. $4 \mathrm{eV}$ ) and chemical stability that lends itself to the possible production of laser facet coatings and MISFETS.

B.M. Basol (International Solar Electric Technology) and R. Noufi (NREL) described recent advances in CuInSe $\mathrm{C}_{2}$ and $\mathrm{Cu}(\mathrm{In}, \mathrm{Ga}) \mathrm{Se}_{2}$ polycrystalline solar cells. Basol described a novel Te interlayer deposition that stabilizes the Mo metallization layer by retarding formation of $\mathrm{MoSe}_{2}$. Noufi described the fabrication of a polycrystalline solar cell that set a thinfilm efficiency record of $15.9 \%$, surpassing a previously reported European university consortium efficiency of $14.9 \%$ announced in January 1993.

A session on interfaces and composites included a presentation by M.J. Hampden-Smith (Univ. of New Mexico) on new synthetic routes to nanoscale materials. Included in the presentation were new lower-temperature routes to Group VI (Cr, Mo, W) metals and carbides. Reaction of these materials with Si to produce silicides as well as metal silicide/ metal carbide composites were also described. J.S. Hale (Univ. of Nebraska) described the optical properties and oxidation resistance of sputtered AIN and related multilayer films. These films are being considered for use in near-earth space applications.

The fabrication of several new nitrides was described, $\left(\mathrm{MgSiN}_{2}\right)$ by M.P.A. Viegers (Philips Laboratories) and $\left(\mathrm{FeWN} \mathrm{N}_{2}, \mathrm{FeMnN} \mathrm{N}_{2}, \mathrm{Nb}_{5} \mathrm{~N}_{6}\right.$, and $\left.\mathrm{Ta}_{5} \mathrm{~N}_{6}\right)$ by H.-C. zur Loye (MIT). These materials have many potential technological applications because of their high strength and hardness yet good thermal conductivity. Like oxides, the electrical conductivity of nitrides can vary orders of magnitude.

Symposium Support: Advanced Research Projects Agency, Alfred University-New York State Center for Advanced Ceramics Technology, Aluminum Research Board, NASA Lewis Research Center.

\section{Complex Fluids Stick, \\ Fold, and Flow}

Symposium O, Complex Fluids, consisted of 84 talks and over 40 posters, covering the static and dynamic properties of complex fluids in bulk and at interfaces. "Complex fluids" denotes a wide variety of materials outside conventional condensed matter physics, including colloidal suspensions, gels, polymer melts or solutions, and surfactant-containing phases. These diverse systems have in common a number of features, including: - Self-assembly. Many complex fluids contain mesoscopic structures that assemble spontaneously from constituent molecules, which are often specially designed to result in a particular self-assembled structure. Amphiphilic molecules, including surfactants and block copolymers, aggregate into a huge variety of structures, including micelles, monolayers, and bilayers.

- Complex rheology. The behavior of complex fluids under deformation and flow is complex for several reasons. The presence of spatially extended structures in such systems leads to slow, nontrivial stress relaxation on the mesoscopic level in contrast to simple fluids. Also, selfassembly can be affected by deformation and flow as the self-assembled structures break, grow, or order under the influence of applied stresses.

- Broad application. Complex fluid systems are ubiquitous in chemical engineering, biology, and materials science; practical examples include paint, motor oil, slurry, ceramic precursors, cosmetics, blood, and disposable diapers.

This symposium focused on selfassembly of surfactants into micelles, monolayers, and bilayers; the resulting phases containing these mesoscopic structures; strongly interacting heterogeneous polymers, including polyelectrolytes, random copolymers, and proteins; the effect of flows on complex fluids; and wetting phenomena in complex fluids.

- Self-assembled monolayers and bilayers. J.V. Selinger (Naval Research Lab.) spoke on monolayers of chiral molecules, and spontaneous chiral symmetry breaking in defect structures in monolayers with tilt order; he related these phenomena to the spontaneous formation of microtubules in certain lipid solutions. J.A.N. Zasadzinski (UC-Santa Barbara) presented experimental studies of monolayers of natural and synthetic lung surfactant; the surface-tension reducing properties of these materials make breathing possible, and synthetic replacements are needed in caring for premature infants.

- Surfactant phases. R. Strey (MaxPlanck-Institut, Gottingen) presented freeze-fracture, neutron-scattering, and interfacial tension studies of microemulsions and $\mathrm{L}_{3}$ (sponge) phases, relating their phase behavior and geometry. G. Porte (Univ. of Montpellier) described temperature-jump experiments on sponge phases in which he observed separate relaxation times for surfactant diffusion, leakage across bilayers, and changes in topology. D. Roux (CRPP, Bordeaux) spoke on the striking effects of shear flow on lyotropic lamellar phases, including the production of monodisperse metastable multilamellar vesicle ("onions"), which can be used as drug encapsulators or as microreactors for controlled chemistry.

- Strongly interacting heteropolymers. J.L. Barratt (ICS, Strasbourg) showed that the long-standing question of the persistence length of a single polyelectrolyte chain is strongly affected by taking into account bending fluctuations, resulting in a persistence length of the order of the Debye screening length. K.A. Dill (UCSan Francisco) described a mode of protein folding in which the driving force for folding is the amphiphilic nature of amino acid groups; he showed with simulations that placing hydrophobic groups on the "inside" of folded configurations greatly reduces the number of folded states. E.I. Shakhnovich (Harvard Univ.) presented models of protein folding 
using random heteropolymers. Using concepts from spin glasses, he showed that while random sequences do not find a folded configuration in a reasonable time, a small amount of rearranging of monomers to favor a given folded state greatly reduces the time for a chain to fold.

- Complex fluids in flow. M. Doi (Nagoya Univ.) discussed the rheology of demixing fluids, and the mechanism by which the shear rate determines the length scale of mixing. J.A. Kornfield (Caltech) presented experimental studies using rheology and birefringence of the shear alignment of block copolymer lamellar phases, which align in a shear flow. E. Herbolzheimer (Exxon) described experiments on a fluidized bed, in which a suspension of particles settles against an upward flow. Using light scattering and transmission measurements, the sedimentation velocity and its variance, diffusivity and shear modulus in the suspension were measured for a wide range of particle volume fraction and interaction strength.

- Wetting behavior of complex fluids. B.J. Frisken (Simon Fraser Univ.) described light and neutron scattering studies of binary fluid mixtures imbibed into silica aerogels. Once proposed as an example of the random field Ising model, these systems appear to have behavior determined by the physics of wetting. In the aerogels, much of the phenomena is explained by growing wetting layers on the gel strands as the critical point is approached, which leads to large shifts in the average composition as a function of position. No unambiguous signature of a surviving critical point has been observed. J.V. Maher (Univ. of Pittsburgh) presented experiments on the aggregation of dilute polystyrene spheres suspended in a binary fluid mixture (lutidine-water) near its critical point. Aggregation was observed by large increases in light scattering and diffusion times for dynamic light scattering. Aggregation occurred near the coexistence curve on the side of the phase diagram poor in the component wetting the spheres. The phenomenon is widely used in separation processes.

Symposium Support: Exxon Research and Engineering Company, Office of Naval Research, University of Delaware.

\section{Disorder in Sand, Fluids, Glasses, and Magnetic Flux Lattices Compared}

Disorder in condensed matter systems ranges from isolated defects in crystal lattices to spatio-temporal chaos in fluid turbulence. In any given system, disorder can extend from atomic to macroscopic length scales over periods ranging from small fractions of a second to geological time scales. Yet, unifying themes, generally characterized by scaling relations, have arisen in the past few years, as presented in Symposium P, Disordered Materials: Fractals, Scaling, and Dynamics.

This symposium emphasized (1) origins and genesis of disorder and (2) measurement and prediction of novel physical phenomena ascribed to disorder.

One featured topic involved the dynamics of periodically driven granular materials. These "sand piles" interact solely through contact forces. Unless specially prepared, an undisturbed sand pile has neither local nor global order. Under vigorous shaking, however, sand piles flow and can develop regular convection rolls within their containers which are visually reminiscent of convection rolls in fluids. These rolls and related waves have been recognized in industrial and geological processes and may have far reaching practical consequences for mixing and unmixing of commercial materials. Still more vigorous shaking induces higherorder excitations which resemble nonlinear fluid waves during the cascade to turbulence. The large-scale flow patterns in this intrinsically disordered system can exhibit either order or extreme disorder. While little is understood yet about the origins of these patterns in driven granular materials, their resemblance to processes in conventional fluids is believed to have fundamental origins.

In this manner, sand is being brought into the same theoretical framework as convecting fluids. In this case, a homogeneous and featureless fluid can be driven by thermal gradients to form regular convection rolls. Under stronger driving, this ordered pattern once again gives way to disorder both in spatial and temporal behavior. Still further from equilibrium, intriguing hints of the reemergence of order have been found. Explaining this surprising behavior remains one of the central challenges of fluid dynamics, despite considerable recent progress. Several experimental groups explored the deep connection between the emergence of characteristic length and time scales in hydrodynamic systems and the development of form in pattern forming systems.

Length scale selection also appears as the central problem in the study of phase separation. In systems as diverse as binary fluid mixtures undergoing spinodal decomposition and embryonic cell clusters segregating into organ systems, incompatible materials must unmix themselves into energetically favorable structures. The processes responsible for this division into compatible domains are not yet fully understood. Experimentally, virtually all such systems exhibit both temporal and spatial scaling during their evolution. This year's experimental announcements include measurements of the influence of geometrical confinement on scaling behavior in these systems.

Fluids have also been used to probe the disorder in porous materials. The fluid's surface tension competes with wetting forces in the material's pores. The interplay of driving, restoring, and pinning forces creates complex structure and dynamics. Among the advances reported this year are new methods for remotely measuring the porosity of rock at the bottom of deep wells. The mechanisms by which fluids invade and flow through porous media and their response to external driving both drew considerable attention. One of the more perplexing questions involves the stability of the interface between an invading fluid and the fluid it displaces. Several mechanisms have been proposed to explain the roughness in these interfaces; theoretical progress reported this year provides experimenters with diagnostic tools to distinguish unambiguously among the competing theories. The evolution of interfacial roughness also has been vigorously investigated in relation to the growth by deposition of advanced engineering materials. Indeed the theoretical approach to these two problems are fundamentally intertwined. In this field, experimental observations have advanced rapidly in tandem with theoretical progress.

The spontaneous evolution of disorder finds its most complete expression in the formation of glasses. This year's symposium included the announcement of the first analytically solvable model which undergoes a glass transition.

The influence of local pinning forces also plays a central role in the dynamics of magnetic flux lattices in type-II superconductors and of sliding charge density waves. In superconducting systems, these considerations lie at the foundation of superconductors' practical applications. Splayed columnar pinning centers were proposed as mediators for flux line entanglement leading to a flux glass in high temperature superconductors. Pinning was experimentally demonstrated to induce a crossover in the dynamics of sliding flux lattices. Under weak pinning, the entire lattice moves coherently while strong pinning induces plastic deforma- 
tion of the lattice, the formation of topological defects, and local failure. The same behavior is also reported in sliding charge density waves. Model systems such as magnetic bubble arrays promise direct probes of this local behavior.

Symposium Support: Exxon Research and Engineering Company, NEC Research Institute Inc., Office of Naval Research, Schlumberger-Doll Research.

\section{Organic Solids Show Off Electrical, Optical, and Magnetic Properties (See MRS Proceedings Volume 328)}

In this 20th anniversary year of the Materials Research Society, it is appropriate that symposia topics emphasize both the long-term significance and the everchanging nature of materials research. Thus, topics in Symposium Q, Electrical, Optical, and Magnetic Properties of Organic Solid State Materials, ranged from those which have been of great importance for the life span of the Society to those recently emerging areas of research focus. Liquid crystals and light emitting organic polymer diodes provide examples of this diversity and, interestingly, both of these materials are of potential utility in the commercial development of flat panel displays.

Molecules and polymers containing pi electrons have been the subject of considerable research for nearly 20 years because of interesting electrical conductivity and superconductivity properties, ferroelectric properties, magnetic properties including ferromagnetism and antiferromagnetism, and a variety of linear and nonlinear optical properties. The 174 contributions to this symposium attest to the high level of interest in organic solid state materials. In some cases, such as liquid crystals and conducting polymers, these organic materials have been translated into commercial products, and research continues to expand the applicability of these materials. In other cases, such as light emitting diodes and photonic materials, materials research appears to have progressed rapidly to the brink of commercial application. For this latter case, this symposium provides an important opportunity to access the exact state of progress and the likely timescale for commercial application. In the case of research into materials for electrooptic modulation, research has expanded from the consideration of optimization of optical nonlinearity to realization that a number of auxiliary properties must be considered for the development of practical modulators. These properties include (1) realization of thermal stability required in

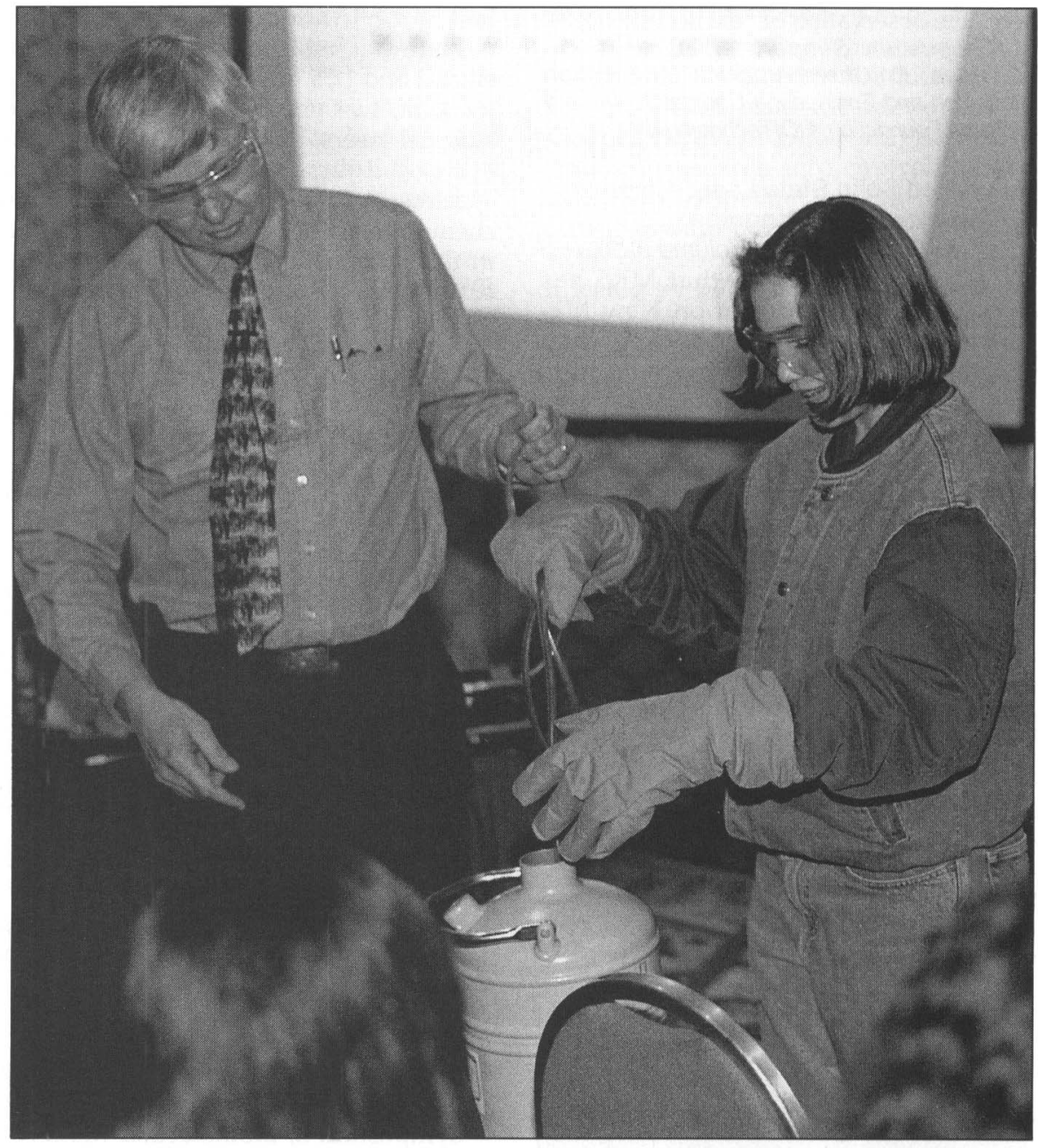

Ken Eckelmeyer, Chair of the Grass Roots Education Committee, assists a Cambridge High School student dip plastic tubing in liquid nitrogen, during a lunchtime session for 50 high school students titled, "How Materials Scientists Vary the Properties of Engineering Materials by Controlling Atomic Bonding and Atomic Arrangement."

various steps of device fabrication, system integration, long term operation and storage; (2) materials characteristics necessary for the fabrication of buried channel waveguide ultrastructures which can be coupled and impedance matched to fiber optic transmission lines; and (3) realization of processing characteristics necessary for polymer/semiconductor integration. Consideration of these additional issues has resulted in dramatically expanded research activities which require information exchange for timely realization of commercial modulators.

Pi electron organic materials are of great interest not only because of their potential technological importance but also because fundamental new chemical and physical insights can be gained from the consideration of these systems. For example, these systems can be viewed as an intermediate case between the extremes of electron localization (e.g., to an atomic orbital) and electron delocalization (band theory). Organic materials are also of interest from the standpoint that synthetic control can be exercised to achieve quasi-electron delocalization in one, two, or three dimensions. Not only were theoretical calculations presented which continue the exploration of the consequences of quasi-electron delocalization in pi-electron organic materials but also new experimental observations 
(e.g., the observation of "exciton strings"). Symposium Support: BIOSYM Technologies, EniChem America Inc., Exxon Research and Engineering Company, National Science Foundation, ROITechnology.

\section{Advanced Solid State Laser Materials Experience Rapid Progress}

(See MRS Proceedings Volume 329)

This is the first time that MRS has sponsored a symposium on New Materials for Solid State Lasers, Symposium $R$. In the past five years, there have been rapid advances in solid state lasers because of the availability of high power semiconductor laser diodes. Combination of the two technologies greatly increases the wall plug efficiency of the lasers (by $10 \mathrm{X}$ ) and at the same time greatly reduces the size of the devices (by 10 to $100 \mathrm{X}$ ), so potential applications are close. To fully take advantage of such resolution, new laser materials are needed.

This symposium revealed new solid state laser materials, nonlinear optical crystals, structures (including fibers, thin films, and waveguides), and growth and manufacturing processes. To make the devices useful, the research effort has concentrated on miniaturization, cost reduction, and wavelength selectivity. Some specific areas of interest include uv

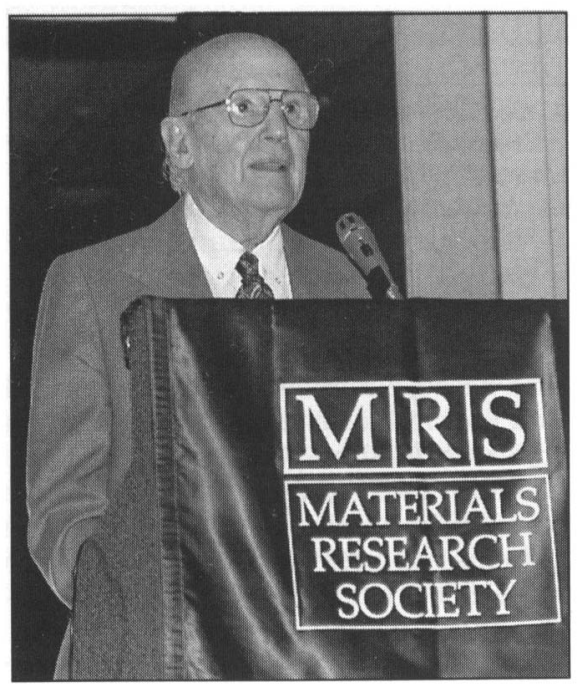

Morris Cohen, 1993 Turnbull Lectureship recipient, expresses his "long-standing admiration and respect for David Tumbull" during the awards ceremony. Cohen will present his Tumbull lecture Wednesday, April 6 during the MRS Spring Meeting in San Francisco. lasers for lithography, blue or green miniature lasers for $C D$ and laser printers, 1.3 and $1.55 \mu \mathrm{m}$ lasers for telecommunication, $1.94 \mu \mathrm{m}$ lasers for fiber guided surgical lasers, 1.55 or $2.1 \mu \mathrm{m}$ lasers for eye safe lidars, and tunable lasers for spectroscopy and selective photo-induced chemical reactions. Some of the highlights in this symposium included the thermal diffusion bonding process to produce quasiphase-matching nonlinear devices by $R$. Byer (Stanford Univ.), which opens a new road to generate mid-ir tunable laser sources; a real assessment of the material requirements for the future $\mathbf{1 5}$ MW inertia confinement fusion laser for commercial power generation by F.W. Krupke (Lawrence Livermore Natl. Lab.); and finally the development of dyedoped sol-gel and plastic lasers by T.H. Allik (SAIC). A new breakthrough was reported by M.T.G. Canva (Univ. Orsay) on the ultralow-loss sol-gel materials.

Materials constraints have limited laser development, but recent progress brightens the outlook for use of high efficiency, compact solid state lasers in the high tech manufacturing industry and for use in home and office information and entertainment applications.

Symposium Support: Lightning Optical Corporation, US Army Night Vision \& ElectroOptics Dir.

\section{Materials Designed Through Biomolecular Synthesis and Assembly (See MRS Proceedings Volume 330)}

Symposium S, Biomolecular Materials by Design, brought together materials scientists who use biological approaches and chemists, biochemists and molecular geneticists responsible for important research in organic synthesis, surface chemistry, and protein engineering. The combination of presentations on new techniques of synthesis and assembly with those on materials applications was so striking and varied that it is impossible to single out highlights. Beginning with organic synthesis, P.E. Nielsen (Univ. of Copenhagen) described PNA (nucleic acids with peptide backbones), which may have therapeutic applications. Then, two quite different and perhaps complementary approaches to the synthesis of nanostructures were described. The first used oligonucleotides as building blocks for three-dimensional structures, the most complex of which was a 14-faceted truncated octahedron of 790 kilodaltons. The second approach is based on self-assembling multi-ring rotaxanes and catenanes.

Findings from structural biology that are relevant to protein engineering were presented by P.S. Kim (MIT), who described polypeptide zippers and springs and D.M. Engelman (Yale Univ.) who gave a detailed analysis, by mutagenesis, of an intramembrane helix-helix interaction. We are just beginning to see successes in designed materials based on these and related structures. If the protein folding problem could be solved it would obviate the need for these preliminaries. The work of H.A. Scheraga (Cornell Univ.) suggests that the theoreticians have much to offer. F.H. Arnold (Caltech) spoke about engineering metal ion binding sites into proteins and on an intriguing development: multinuclear metal complexes that bind to proteins by coordinating distant residues. D. Hilvert (Scripps) spoke about new findings on the mechanism of antibody catalysis based on data from a crystal structure. The properties of silk and progress towards the production of recombinant silk proteins were summarized. Achievement of the elusive latter goal will represent a landmark in biomolecular materials research.

Biomineralization and ceramics talks occupied an entire day. I.A. Aksay (Princeton Univ.) presented data on microceramic particles whose shape could be controlled during synthesis by using electromagnetic fields. S.I. Stupp (Univ. of Illinois, Urbana) described organoapatites with built-in anti-inflammatory agents and bioadhesives for use in artificial bone. The self-assembly of macrofibers from bacteria was demonstrated with the aid of a video by N.H. Mendelsohn (Univ. of Arizona), who also brought samples of extraordinary mineralized drawn fibers called bionites. Recent work on biological and biomimetic mineralization was also described. The potential of crosslinked enzymes microcrystals (CLECs) in biotechnology were described by M.A. Navia (Vertex). These extremely hardy, catalytically active structures generated a long question and answer period. L.J. DeLucas (Univ. of Alabama) described high quality protein crystals he grew on a space shuttle mission. New aspects of surface chemistry were outlined by several speakers including M.S. Wrighton (MIT), who described electrodes derivatized with oligonucleotides for sensor technology, G.M. Whitesides (Harvard Univ.), who spoke on designing surfaces for biological interactions, W. Knoll (Max-Planck-Institut, Mainz), who presented advanced techniques for preparing complex assemblies at surfaces and M. Grunze (Univ. of Heidelberg), who is using acoustic plate 
mode sensors to examine antibody-antigen interactions. In his memorable presentation, Whitesides showed a forlorn cell confined to a microscopic biocompatible rectangle in a sea of incompatibility. The cell had filled and taken on the shape of its island. Growth but not metabolism was arrested before the critical volume for division was reached. The power of analytical techniques for surfaces, including time-resolved methods based on synchrotron x-radiation, was vividly demonstrated by M. Caffrey (Ohio State Univ.). Practical applications of surface derivatization included biocompatible molded plastics (E.R. Stedronsky, Protein Polymer Technologies). The formation, characterization and applications of twodimensional protein crystals including Slayers were covered by U.B. Sleytr (Univ. für Bodenkultur) and $H$. Engelhardt (Max-Planck-Institut, Martinsried). S-layers have been used in ultrafiltration devices, to immobilize other proteins in regular arrays (Sleytr) and as templates for the formation of metallic nanostructures that can in turn be used as masks for the patterning of silicon surfaces (N.A. Clark, Univ. of Colorado). H.P. Bayley (Worcester Foundation) described genetically-engineered pore-forming proteins with activities that can be triggered or switched on and off by biochemical and chemical stimuli. Such pores might be used as components of biosensors ( $\mathrm{J}$. Kasianowicz, NIST) conceivably by incorporating them into long-lived bilayers at the tips of thin platinum wires (A. Leitmannova-Ottova, Michigan State). Bioelectronics was the subject of an intense session. Much of the discussion centered on bacteriorhodopsin and its mutants, which have properties that are highly favorable for applications such as optical data storage and holographic pattern recognition. Other approaches in bioelectronics included the use of tRNA molecules to nucleate $\mathrm{CdS}$ quantum dots. In the final session on smart materials, D.H. Charych (Lawrence Berkeley Lab.) detailed studies on the detection of virusligand interactions using functionalized mechanichromic films. Designed proteins that can interconvert various combinations of mechanical, thermal, pressure, chemical, electrical and photochemical energy were described by D.W. Urry (Univ. of Alabama, Birmingham). Polypyrrole films that generate force through a redox mechanism have been produced by T.F. Otero (Univ. of the Basque Country). The Symposium closed with a colorful update on what is known of the mechanisms of molecular motors found in nature (H.C. Berg, Harvard Univ.) One now senses that the field of biomolecular materials is on the verge of absorbing the astonishing recent advances in chemistry and molecular biology and thereby producing new substances that until now have only been imagined by materials scientists.

Symposium Support: Alpha-Beta Technologies, Department of Energy, DuPont, Johnson \& Johnson, Monsanto, Office of Naval Research (through Worcester Foundation), Vertex Pharmaceuticals.

\section{Biomaterials Developed for Drug and Cell Delivery}

(See MRS Proceedings Volume 331)

Fifty-five speakers presented their research results in five sessions at Symposium T, Biomaterials for Cell and Drug Delivery. The symposium started with a presentation by I.V. Yannas (MIT) describing the use of engineered materials for tissue regeneration. Several speakers next presented advances in the development of materials for regeneration of nerves, ligaments, tendons, and bone. This was followed with discussions of novel matrices for cell transplantation, with particular emphasis on hepatocytes.

D.A. Tirrell (Univ. of Mass.) discussed the synthesis and use of hybrid proteins which contain both natural and artificial amino acids. Next came presentations on biomaterials for targeted or controlledrelease drug delivery. These speakers described efforts in improving the bio-

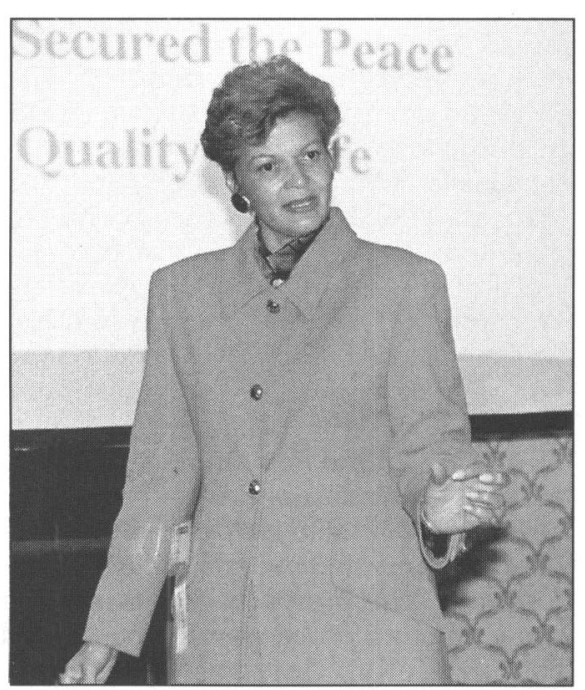

Hazel O'Leary, the Department of Energy Secretary, gives the plenary presentation. degradative, bioerosive, specificity, and release characteristics of these materials.

The focus switched in the third session to cell-biomaterial interactions. S.L. Cooper (Univ. of Delaware) described ongoing research into controlling cell adhesion properties by grafting RGD peptides onto polyurethanes. R. Bizios (RPI) discussed how cellular function is affected by bioactive peptides immobilized onto surfaces. Next came several talks on osteoblast and hepatocyte adhesion and function in response to biomaterials, integrin-mediated cell-surface stabilization, cell proliferation in membranes, and diffusion limitations in encapsulated cells. One of this session's highlights was a presentation by J.Y. Wong (MIT) on cell interactions with fibronectin-coated electrically conducting polypyrrole thin films, for which she received an MRS Graduate Student Award.

W. Rubas (Genentech) and W.M. Saltzman (Johns Hopkins) began the fourth session with talks on transport in intestinal tissues and controlled release of neurotrophic factors, respectively. These were followed by several presentations on advances in the development of hydrogels and other novel materials for controlled drug release. The final session focused on experimental methods for the characterization of biomaterials and developments in orthopedic biomaterials. B. Ratner (Univ. of Washington) began with a discussion of the latest surface analytical tools for improving understanding of the structure, chemistry, and performance of engineered biomaterials. Papers on the use of FTIR and XPS followed. The session was rounded out with several presentations on the use of polymeric or inorganic materials for bone repair, replacement, or regeneration.

Symposium Support: Alkermes, Biotransplant Inc., Birmingham Polymers Inc., Focal Inc., Genentech Inc., PerSeptive Biosystems Inc., Pfizer Central Research, Shering Plough Research Institute, Synergy, Theratech, The West Company.

\section{Microscopy and Spectroscopy Directly Reveal Physical Properties (See MRS Proceedings Volume 332)}

As the capabilities of microscopy techniques to investigate materials at smaller dimensions improve, the processing techniques advance in parallel that allow materials synthesis with better-controlled spatial variations at a smaller scale, as demonstrated in many areas of materials and biological sciences. Symposium U, Determining Physical Properties of Materials by Microscopy and Spectro- 
scopy, demonstrated that in addition to using microscopy and spectroscopy techniques for imaging and compositional and chemical analysis, these newly emerging techniques are capable of directly measuring physical and chemical properties of nanostructured biological and synthesized materials at a local scale.

Microscopy techniques included those that use photons, $x$-rays, electrons, and scanning probe techniques at their highest resolutions, all less than $1,000 \AA$ down to nanometer and molecular levels, and in some cases $1 \AA$ and smaller dimension. Similarly, spectroscopy techniques included local measurements of bonding, electronic, optical, and magnetic properties, again using probes at the nanometer scale.

Breaking the resolution limit in the optical microscope, traditionally limited by aberration due to light scattering, we have witnessed that the near-field scanning optical microscope (NSOM) can now image surfaces (wet or dry) with ease at an order of resolution beyond the previous limit. J. Kirz (SUNY) and H. Ade (NCSU) showed that $x$-ray microscopy (XRM) and chemical contrast produce structural and chemical bulk-imaging from wet synthetic and biological materials with resolution down to a few hundred nanometers, with a potential to go even further down.

We have learned from D.J. Smith (ASU) and M.A. O'Keefe (Lawrence Berkeley Lab.) that conventional atomic resolution TEM provides images with better than $2 \AA$ resolution both in projection and in 3-D. With coherent imaging, provided by the new field emission TEM instruments ( $\mathrm{H}$. Lichte, Univ. Tubingen) and incoherent imaging with dedicated STEM instruments (S.J. Pennycook, Oak Ridge Natl. Lab. and J. Silcox, Cornell Univ.) the resolution limit seems to have gone down to $1 \AA$ in the electron microscope. Furthermore, as beautifully demonstrated by Pennycook and P. Schwander/A. Ourmazd et al. (AT\&T, Holmdel), it is now possible to chemically image atoms in projection by STEM and TEM, both with FEG sources, respectively. Universally the most practical of all imaging techniques, i.e., scanning electron microscopy (SEM), now at subnanometer-level resolution, was demonstrated, with great humor, by D.C. Joy (Univ. of Tennessee). We now know from P.E. Batson's (IBM-Yorktown Heights) and E.A. Stern's (Univ. of Washington) presentations that, using electron energy loss spectroscopy (EELS) in the TEM, it is possible to obtain information about bonding energies, oxidation states, and short range ordering in areas from 1,000 $\AA$ down to as small as $2 \AA$ diameter (defined by the electron probe) using energy loss near edge structure analysis (ELNES) and extended energy loss fine structure analysis (EXELFS), respectively. Parts-per-million level elemental analysis by energy dispersive $x$-ray (EDX) and EELS were discussed heatedly by D.B. Williams (Lehigh Univ.), D.E. Newbury (NIST) and A.J. Garrat-Reed (MIT). Elemental imaging at the highest resolution levels using energy filtering was skillfully illustrated by O.L. Krivanek (Gatan) in engineering materials with a conventional TEM and, with the same rigor, by R.D. Leapman (NIH) in biological samples with a STEM. With an FEGTEM, we learned that it is now possible to obtain diffraction directly from nanoscale areas (interfaces, multilayers, defects) to decipher structures using convergent beam electron diffraction (CBED), well represented by J.W. Steeds (Univ. of Bristol).

The latest developments in imaging and spectroscopy with scanning probe microscopies were also well represented. Imaging and interface structure at angstrom dimensions and electrical properties below the eV level with scanning tunneling microscopy (STM) were demonstrated by R.M. Feenstra (IBM, Yorktown Heights), H.W.M. Salemink (IBM, Zurich) and R.V. Coleman (Univ. of Virginia). H.D. Hallen et al. (NCSU) and M.R. Scheinfein (ASU) demonstrated measurements of magnetic and dynamic superconducting properties with STM, respectively. Molecular imaging with STM and atomic force microscopy (AFM) in fluids was demonstrated by experimentalists, S.M. Lindsay (ASU) and P.K. Hansma (UCSB), respectively, and the problems in STM imaging of proteins were discussed by B. Ratner (Univ. of Washington). Imaging electron standing waves, enclosed in a quantum corral on an Fe surface, was elegantly demonstrated by D.M. Eigler (IBM, Almaden) showing us directly for the first time that electrons are really waves!

Although limited by sample preparation to conductive materials, current status and future prospects of 3-D imaging using an atom probe were demonstrated by T.F. Kelly (Univ. of Wisconsin). Dynamic imaging, in projection, of atomic diffusion in precipitate growth in metals was demonstrated by J.M. Howe (Univ. of Virginia) and flux-line dynamics in low and, surprisingly, high temperature superconductors was clearly demon- strated by A. Tonomura (Hitachi). Dynamic properties of surfaces were discussed by several researchers. J.N. Israelachvili (UCSB) described dynamic properties of phase states of fluids at interfaces; B.A. Parkinson (Colorado State Univ.) covered 2-D growth with STM, and other speakers presented elastic, thermal, and tribological studies.

It was exciting to hear about relatively new techniques in molecular imaging. J.C.H. Spence (ASU) demonstrated the possibilities of imaging thin membranes (<20 $\AA$ ) with low-voltage point-projection microscopy. A truly revolutionary technique, NMR imaging, both in theory and experiment (represented, respectively, by J.A. Sidles, Univ. of Washington, and D. Rugar, IBM, Almaden) appeared to have set a new era in the quest for imaging structures at the sub-angstrom level and in 3-D, i.e. recognizing atoms and their bonding states and biological molecules.

Symposium Support: Digital Instruments, JEOL, National Science Foundation (through Univ. of Washington), Office of Naval Research.

\section{Successful Repository Implementation Slowed by Required 10,000 Year Prediction}

(See MRS Proceedings Volume 333)

The 17th Symposium on the Scientific Basis for Nuclear Waste Management, Symposium V, included 127 papers given by scientists from 16 countries. The opening part of the symposium was dedicated to an overview and evaluation of the progress of nuclear waste management science and technology. Eighteen papers, given by prominent participants in the United States and international nuclear waste management programs, surveyed achievements to date, issues calling for further research, and the limitations of the scientific method in addressing the issue of nuclear waste management. Although different speakers emphasized different aspects of the nuclear waste problem, consensus appeared to emerge on two critical points. First, although the scientific data gathered so far have been very useful in clarifying issues related to the future performance of a waste repository, success in implementing the repository concept is not likely as long as the regulations for waste disposal call for detailed predictions over a period of 10,000 years. Secondly, the choice of solutions for specific types of nuclear waste should be flexible during early stages of the waste disposal process so as to take maximum advantages of data obtained during this early period and of future advances in technology. 
The other papers presented at the symposium described the progress of studies in a broad array of areas of nuclear waste science and technology. These areas included radiation effects and gas generation, ceramic materials, cementitious materials, actinides and spent fuel, glass processing and properties, glass leaching, dissolution and alteration, natural and ancient analogues, transuranic wastes and special wastes, sorption mechanisms, repository studies, geochemistry and hydrology, containers, and backfill materials. Several novel experimental techniques were described, as well as advances in modeling. An encouraging feature of the progress in modeling is that the agreement between calculated results based on models developed, refined, and tested and experimental data shows considerable improvement. This reflects greater understanding of the mechanisms involved in the release of radionuclides from the various components of the waste repository system, including the wasteform itself. However, the papers presented at the symposium indicate that further work on model refinement and validation is necessary as well as better communications between scientists on one hand, and policy-makers and regulators on the other.

Symposium Support: Department of Energy, Nuclear Regulatory Commission.

\section{Electronic Materials Processing Relies on Gas-Phase and Surface Chemistry (See MRS Proceedings Volume 334)}

The four-day symposium on Gas-Phase and Surface Chemistry in Electronic Materials Processing, Symposium W, contained 116 technical presentations covering recent developments in vaporphase thin-film processing for microelectronics. It particularly emphasized chemistry and its effect on film quality. Materials considered in this symposium included silicon and compound semiconductor systems, carbon systems, metals, insulators, and optical materials.

Specific developments were presented on (1) the deposition chemistry of silicon and compound semiconductors; (2) new precursors for deposition of compound semiconductors and metals; (3) selective metallization; (4) deposition of dielectrics;
(5) new chemistry for etching of thin films; (6) the chemistry of diamond film growth; and (7) chemical aspects of heteroepitaxy, selective epitaxy and growth on patterned substrates.

Symposium Support: Army Research Office, Office of Naval Research.

\section{MOCVD Precursors and Source Delivery Important for Electronic Ceramics}

(See MRS Proceedings Volume 335)

One of the important new methods for preparing thin film oxides and nitrides for electronic and photonic applications is metal-organic chemical vapor deposition (MOCVD). Symposium Y, Metal-Organic Chemical Vapor Deposition of Electronic Ceramics, focused on a number of aspects key to the further development of this technique including new precursors, pre cursor delivery systems, deposition chemistry, system modeling and applica- tions. A total of 70 papers were presented. Of particular interest were the advances in liquid and solid source delivery systems. Marked improvements in film composition control and thickness uniformity were noted. The fluorinated organometallic precursors showed considerable promise as stable volatile sources for a wide variety of oxides. The utilization of MOCVD for a number of applications such as dielectrics, electrooptic and high $\mathrm{T}_{c}$ superconductor materials was reported, demonstrating the versatility of the technique.

Symposium Support: IBM T.J. Watson Research Center, NASA Lewis Research Center.

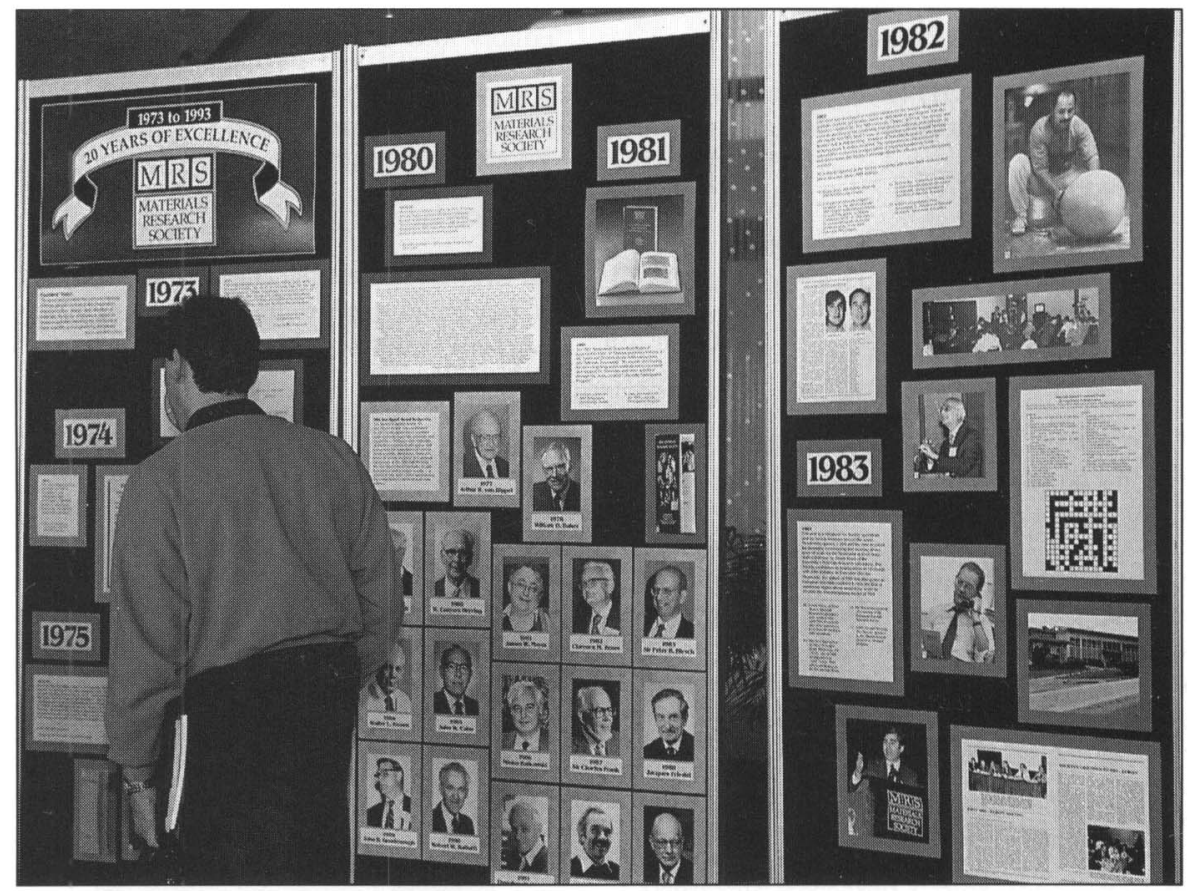

A special display at the Fall Meeting depicts the milestones that celebrate "20 Years of Excellence" for the Materials Research Society. See the September 1993 MRS Bulletin, p. 73-87, for a description of MRS's 20-year history and the people that made it happen.

\section{MRS Fall Meeting Proceedings ... see pg. 80.}




\section{MRS 1993 FALL MEETING \\ MATIRIATS RFSEARC II \\ $S(\mathrm{IEI}$ SYMPOSIUM PROCEEDINGS}

Place your order today for proceedings of the 1993 MRS Fall Meeting in Boston.

A: Materials Synthesis and Processing Using Ion Beams

Editors: R.J. Culbertson, K.S. Jones,

O.W. Holland, K. Maex

ISBN: 1-55899-215-4

$\$ 70$ MRS Members

Code: 316

$\$ 80$ U.S. List

$\$ 85$ Foreign

\section{B: Mechanisms of Thin Film Evolution}

Editors: S.M. Yalisove, C.V. Thompson,

D.J. Eaglesham

ISBN: 1-55899-216-2

Code: 317

$\$ 63$ MRS Members

$\$ 73$ U.S. List

$\$ 78$ Foreign

Ca: Interface Control of Electrical, Chemical, and Mechanical Properties

Editors: S.P. Murarka, T. Ohmi, K. Rose, T. Seidel

ISBN: $1-55899-217-0$

Code: 318

$\$ 70$ MRS Members

$\$ 80$ U.S. List

$\$ 85$ Foreign

$\mathrm{Cb}$ : Defect-Interface Interactions

Editors: E.P. Kvam, A.H. King, M.J. Mills,

T.D. Sands, V. Vitek

ISBN: 1-55899-218-9

$\$ 61$ MRS Members

Code: 319

$\$ 71$ U.S. List

$\$ 76$ Foreign

D: Silicides, Germanides, and Their Interfaces

Editors: R.W. Fathauer, L. Schowalter,

S. Mantl, K.N. Tu

ISBN: 1-55899-219-7

$\$ 61$ MRS Members

$\$ 71$ U.S. List

$\$ 76$ Foreign

E: Crystallization and Related Phenomena in Amorphous Materials - Ceramics, Metals,

Polymers, and Semiconductors

Editors: M. Libera, T.E. Haynes, P. Cebe,

J. Dickinson

ISBN: 1-55899-220-0

$\$ 68$ MRS Members

$\$ 78$ U.S. List

$\$ 83$ Foreign

F: High-Temperature Silicides and

Refractory Alloys

Editors: B.P. Bewlay, J.J. Petrovic, C.L. Briant, A.K. Vasudevan, H.A. Lipsitt

ISBN: 1-55899-221-9

$\$ 63$ MRS Members

$\$ 73$ U.S. List

$\$ 78$ Foreign
J: Electronic Packaging Materials Science VII Editors: R. Pollak, P. Børgesen, H. Yamada, K.F. Jensen

ISBN: 1-55899-222-7

Code: 323

$\$ 61$ MRS Members

$\$ 71$ U.S. List

$\$ 76$ Foreign

K: Diagnostic Techniques for Semiconductor

Materials Processing

Editors: O.J. Glembocki, F.H. Pollak,

S.W. Pang, G. Larrabee, G.M. Crean

ISBN: 1-55899-223-5

Code: 324

$\$ 61$ MRS Members

$\$ 71$ U.S. List

$\$ 76$ Foreign

L: Defects in Advanced Semiconductors:

Physics and Applications

Editors: M.O. Manasreh, M. Lannoo,

H.J. von Bardeleben, E.L. Hu,

G.S. Pomrenke, D.N. Talwar

ISBN: 1-55899-224-3

$\$ 61$ MRS Members

$\$ 71$ U.S. List

$\$ 76$ Foreign

M: Growth, Processing, and Characterization of Semiconductor Heterostructures

Editors: G. Gumbs, S. Luryi, B. Weiss,

G.W. Wicks

ISBN: 1-55899-225-1

Code: 326

$\$ 64$ MRS Members

$\$ 74$ U.S. List

$\$ 79$ Foreign

N: Covalent Ceramics II: Non-Oxides

Editors: A.R. Barron, G.S. Fischman,

M.A. Fury, A.F. Hepp

ISBN: $1-55899-226-X$

$\$ 68$ MRS Members

Code: 327

$\$ 78$ U.S. List

$\$ 83$ Foreign

Q: Electrical, Optical, and Magnetic

Properties of Organic Solid State Materials

Editors: A.F. Garito, A. K-Y. Jen, L.R. Dalton,

C. Lee

ISBN: $1-55899-227-8$

$\$ 68$ MRS Members

$\$ 78$ U.S. List

$\$ 83$ Foreign

R: New Materials for Advanced

Solid State Lasers

Editors: B.H.T. Chai, T.Y. Fan, S.A. Payne,

A. Cassanho, T.H. Allik

ISBN: 1-55899-228-6

$\$ 64$ MRS Members

Code: 329

$\$ 74$ U.S. List

$\$ 79$ Foreign
S: Biomolecular Materials By Design

Editors: H. Bayley, D. Kaplan, M. Navia

ISBN: 1-55899-229-4 Code: 330

$\$ 68$ MRS Members

$\$ 78$ U.S. List

$\$ 83$ Foreign

T: Biomaterials for Drug and Cell Delivery

Editors: A.G. Mikos, R. Murphy,

H. Bernstein, N.A. Peppas

ISBN: 1-55899-230-8

Code: 331

$\$ 68$ MRS Members

$\$ 78$ U.S. List

$\$ 83$ Foreign

U: Determining Nanoscale Physical

Properties of Materials by Microscopy and

Spectroscopy

Editors: M. Sarikaya, M. Isaacson,

H. K. Wickramasighe

ISBN: 1-55899-231-6

$\$ 64$ MRS Members

Code: 332

$\$ 74$ U.S. List

$\$ 79$ Foreign

V: Scientific Basis for Nuclear Waste

Management XVII

Editors: A. Barkatt, R. Van Konynenburg

ISBN : 1-55899-232-4

Code: 333

\$68 MRS Members

$\$ 78$ U.S. List

$\$ 83$ Foreign

W: Gas-Phase and Surface Chemistry in

Electronic Materials Processing

Editors: T.J. Mountziaris, P.R. Westmoreland

F.T.J. Smith, G.R. Paz-Pujalt

ISBN: 1-55899-233-2

Code: 334

$\$ 64$ MRS Members

$\$ 74$ U.S. List

$\$ 79$ Foreign

Y: Metal-Organic Chemical Vapor Deposition of Electronic Ceramics

Editors: S.B. Desu, D.B. Beach, B.W. Wessels, S. Gokoglu

ISBN: 1-55899-234-0

Code: 335

$\$ 61$ MRS Members

$\$ 71$ U.S. List

$\$ 76$ Foreign

\section{Scheduled for publication by}

spring or early summer 1994.

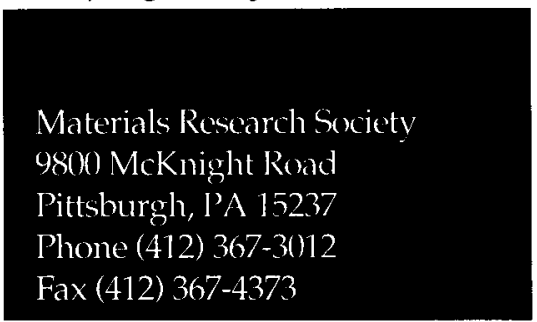

940046 